\title{
Comparison of the effectiveness of 11 mainstay treatments for secondary prophylaxis of variceal bleeding in patients with cirrhosis: A network meta-analysis
}

\author{
$\mathrm{YU} \mathrm{KONG}^{1}$ and $\mathrm{LIANG} \mathrm{SHI}^{2}$ \\ ${ }^{1}$ Second Department of Gastroenterology; ${ }^{2}$ Endoscopy Division, \\ Department of General Surgery, Cangzhou Central Hospital, Cangzhou, Hebei 061001, P.R. China
}

Received March 7, 2019; Accepted December 5, 2019

DOI: $10.3892 /$ etm.2020.8633

\begin{abstract}
The purpose of the present study was to compare the effectiveness of the transjugular intrahepatic portosystemic shunt (TIPS), endoscopic options, medications and mainstay combination therapies for patients with cirrhosis who have had at least one episode of variceal haemorrhage. The PubMed, Embase, Cochrane Library and Web of Science databases, as well as the reference lists of relevant articles, were searched to identify eligible studies. P-scores, that were based solely on the point estimates and standard errors of the network estimates, were performed to rank all treatments, on a scale from 0 (worst) to 1 (best). The odds ratio (OR) was determined to assess effects on mortality, treatment failure and bleeding from gastroesophageal ulcers. A total of 43 randomized controlled trials comprising 3,787 adult patients were included. In total, $26(61 \%)$ trials adopted concealed randomization, while most studies did not specify blinding. The drug combination of nadolol and isosorbide mononitrate (ISMN) ranked first for lowering risks of overall mortality $(\mathrm{P}$-score $=0.8162)$, mortality due to liver failure $(\mathrm{P}$-score $=0.7536)$ and bleeding from gastroesophageal ulcers $(\mathrm{P}$-score $=0.7536)$. This combination was determined to be superior to endoscopic sclerotherapy $(\mathrm{ES})$ alone $(\mathrm{OR}=0.63$, 95\% CI: 0.42-0.94) and TIPS alone in reducing overall mortality $(\mathrm{OR}=0.62$, 95\% CI: 0.40-0.96). ES was more likely to increase treatment failure compared with TIPS, endoscopic variceal liga-
\end{abstract}

Correspondence to: $\mathrm{Dr} \mathrm{Yu}$ Kong, Second Department of Gastroenterology, Cangzhou Central Hospital, 16 West Xinhua Road, Cangzhou, Hebei 061001, P.R. China

E-mail: 2005kongyu@163.com

Abbreviations: AASLD, American Association for the Study of Liver Diseases; ES, endoscopic sclerotherapy; EVL, endoscopic variceal ligation; ISMN, isosorbide mononitrate; NSBB, non-selective $\beta$-blockers; OR, odds ratio; RCT, randomized controlled trial; TIPS, transjugular intrahepatic portosystemic shunt

Key words: secondary prevention, variceal bleeding, mortality, liver cirrhosis, network meta-analysis tion (EVL), ES plus EVL, EVL plus nadolol/propranolol plus ISMN and nadolol/propranolol plus ISMN. In conclusion, the present network meta-analysis suggested that for a decreased mortality due to variceal rebleeding in patients with cirrhosis, nadolol plus ISMN may be a preferable choice, while ES is associated with a higher risk of unfavourable treatment outcomes. Further well-controlled studies are required to further elucidate the appropriate treatment options.

\section{Introduction}

Approximately $30 \%$ of patients with cirrhosis have oesophageal varices at the time of diagnosis; this proportion increases with time and reaches $90 \%$ after $\sim 10$ years (1). Patients with oesophageal varices have a high tendency to develop bleeding. Only 10-20\% of variceal bleeding occurs from gastric varices, but the associated outcome is worse than that of bleeding from oesophageal varices (2-5). Patients surviving a variceal bleed are at high risk of rebleeding ( $>60 \%$ in the first year) and the mortality of each rebleeding episode is $\sim 20 \%$ (6). Therefore, prevention of recurrent variceal bleeding is important for patients with cirrhosis.

For secondary prophylaxis of variceal bleeding, the goal of improving outcomes is evolving, since therapy in these cases attempts to reduce the risk of death, and thus prevent the onset of complications of cirrhosis that may lead to death (1). The treatment effectiveness of secondary preventions, including endoscopic ligation or endoscopic sclerotherapy (ES), drug therapies [non-selective $\beta$-blockers (NSBB) with or without isosorbide mononitrate (ISMN)] and transjugular intrahepatic portosystemic shunts (TIPS) is an area of interest, but at present, a firm consensus as to the most effective treatment has not been reached. Several randomized controlled trials (RCTs) have investigated treatment outcomes in terms of mortality, complications and adverse effects (7-12). A previous study compared endoscopic variceal ligation (EVL) with a combination of EVL and nadolol and identified that adverse effects more frequently occurred in the EVL plus nadolol group (0.03 vs. 33\%) (12). Another trial compared nadolol plus ISMN alone with EVL plus the drug combination and observed that the combination of EVL and drugs led to more adverse effects (62 vs. 32\%), but there were no significant differences in either 
mortality or the causes of death (11). However, a previous direct meta-analysis comprising 925 patients comparing endoscopic therapy with a combination of BB and endoscopic therapy identified that mortality at 24 months was significantly lower in the combined treatment group (13). In addition to inconsistent results among the previous trials and analyses, to the best of our knowledge, there has been no previous network meta-analysis to compare treatment outcomes. Therefore, the present study was performed to compare the effectiveness of standard treatments for the secondary prevention of variceal bleeding in patients with cirrhosis through a network meta-analysis. The specific treatments studied were TIPS, endoscopic therapy (EVL alone or ES alone), a combination of EVL and ES, a combination of EVL/ES and NSBB (propranolol and nadolol) with or without ISMN, as well as a combination of NSBB and ISMN.

\section{Materials and methods}

Literature search. Searches were performed in the electronic PubMed, Cochrane Library, Embase and Web of Science databases in February 2018. The following search terms were used: 'Cirrhotic patients', 'patients with cirrhosis', 'liver cirrhosis', 'haemorrhage', 'bleeding', 'rebleeding', 'variceal', 'oesophageal varices', 'endoscopic variceal ligation', 'endoscopic band ligation', 'endoscopic ligation', 'endoscopic sclerotherapy', 'sclerotherapy', 'endoscopic therapy', 'vasoconstrictors', 'venodilators', 'adrenergic beta antagonist', 'adrenergic-beta antagonist', 'adrenergic beta-antagonist', 'adrenergic-beta-antagonist', 'nitrate', 'beta-blocker', 'isosorbide mononitrate', 'placebo', 'TIPS', 'transjugular intrahepatic portosystemic shunt' and 'randomized controlled trial'. Manual searches of reference lists of relevant articles were also performed to identify additional studies. Only RCTs were included.

Inclusion and exclusion criteria. RCTs, irrespective of publication status, were included if they investigated endoscopic therapy with various combinations of NSBB and ISMN, or TIPS alone among adult patients with cirrhosis, who had at least one previous episode of upper gastrointestinal bleeding. Trials fulfilling the following criteria were excluded: i) Focus on primary prevention of variceal bleeding; ii) inclusion of pediatric patients or patients without cirrhosis; iii) comparison of only one of the aforementioned treatment regimens with other treatment(s), as it was impossible to make a network comparison; or iv) a clearly irrelevant topic, e.g. nutrition after variceal bleeding.

Study selection. Only RCTs whose reports were available in English or Chinese were included. If a trial was designed with more than two treatment arms, at least two of the arms had to match the scope of the present study.

Data extraction. According to the newly published guidelines of the American Association for the Study of Liver Diseases (AASLD) and consensus (14), therapies for secondary prophylaxis must account for the presence or absence of other complications of cirrhosis. In patients with a low risk of death (those with variceal haemorrhage as the sole complication of cirrhosis), the objective of therapy should be the prevention of an additional complication, whereas in patients with a high risk of death (those with variceal haemorrhage and other decompensating events), the objective of therapy should be to improve survival $(15,16)$. Mortality (overall mortality, mortality due to rebleeding and mortality due to liver failure), treatment failure and complications (bleeding from gastroesophageal ulcer) were analyzed.

Data of treatment failure were analyzed when clearly stated in the literature, with exclusion of data that satisfied certain criteria but lacked declaration of treatment failure. Authors of the included trials were not approached for further data due to the large number of RCTs selected and acquisition of adequate data associated with treatment outcomes. The primary outcomes were overall mortality, mortality due to rebleeding, including but not limited to recurrent variceal bleeding and mortality due to liver failure. Overall mortality was defined as death that occurred during the trial treatment or follow-up caused by disease progression or treatment complications. Secondary outcomes were treatment failure and bleeding from gastroesophageal ulcers, including but not limited to post-banding ulcers.

Methodological quality. A bias assessment was performed for the included trials by evaluating randomization, completion of trials and blinding. The major targets were concealment randomization, participant blinding, health care provider blinding, data collector blinding, outcome assessor blinding and early trial cessation.

Randomization was considered concealed if it involved a third independent party or person not involved in the treatment of patients, opaque sealed envelopes or a similar method. Trials were not considered to feature early cessation unless premature termination was specifically announced in the article.

Statistical analysis. The odds ratio (OR) was used to denote the results with a $95 \% \mathrm{CI}$, indicating the strength of association between treatments and outcomes. An OR $<1$ represents the benefit of the comparison group compared with the control group. Pooled ORs and their 95\% CIs were also calculated. Statistical significance was established with a two-sided $\mathrm{P}<0.05$ or a $\mathrm{CI}$ that did not include a value of 1 . The risk ratio was not used to measure outcomes due to limited data regarding the number of events among the selected trials.

To assess the comparability of the included trials, a heterogeneity analysis was performed. Since inconsistency is a source of heterogeneity in network meta-analyses, a generalized Cochran's $Q$ statistic $\left(\mathrm{Q}^{\text {total }}\right)$ and $\mathrm{I}^{2}$ statistic were adopted for assessment of homogeneity and consistency assumptions. Statistical heterogeneity was considered significant when $\mathrm{P}<0.10$ for the $\mathrm{Q}$-test or $\mathrm{I}^{2}<50 \%$. The network meta-analysis used fixed-effects models with $\mathrm{I}^{2}$ values of $0 \%$ for overall mortality, mortality due to rebleeding, mortality due to liver failure and bleeding from a gastroesophageal ulcer, and $I^{2}=29.4 \%$ for treatment failure.

All treatments were ranked according to P-score, which is on a scale from 0 (worst) to 1 (best). P-scores are based solely on the point estimates and standard errors of the most frequent network meta-analysis estimates under normality assumption, 
Flow diagram of the study search and selection process

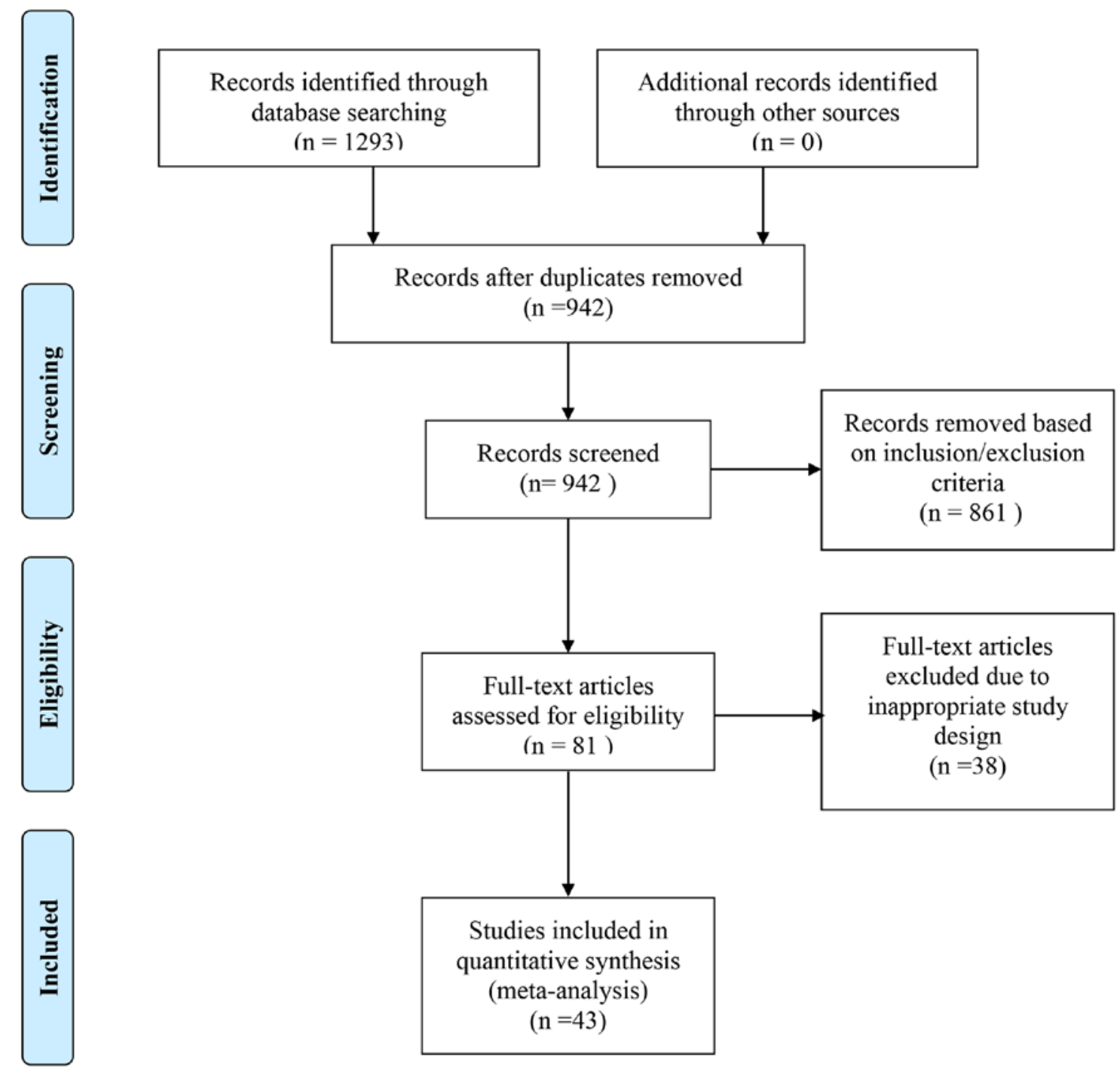

Figure 1. Flow diagram of the study search and selection process.

and can easily be calculated as means of one-sided P-values. They measure the extent of certainty that a treatment is better than another treatment, averaged over all competing treatments (17). Sensitivity analysis was performed by removal of trials with a mean follow-up of $<6$ months. The network meta-analyses were performed using $\mathrm{R}$ 3.3.1 along with the 'netmeta' package by Schwarzer et al (18).

\section{Results}

Search results. Electronic and manual searches identified 1,293 records in total. Following screening of titles and abstracts, 861 references were excluded and the remainder was subjected to full-text screening. Among the excluded studies were duplicates, non-RCTs, trials investigating other treatments, or those covering different topics or focusing on primary prevention of variceal bleeding, due to inadequate data for the present study or randomizing patients without cirrhosis. A previous trial investigating the effects of carvedilol plus EVL was excluded, as it assessed hemodynamic responses but not mortality (19). The screening process followed the Preferred Reporting Items for Systematic Reviews and Meta-Analyses (PRISMA) guidelines and is depicted in a flow chart in Fig. 1.

Characteristics of the studies included. A total of 43 trials (20-62) with a total sample size of 3,787 patients with cirrhosis were included for quantitative network meta-analysis. In total, 5 references were published or available as abstracts $(22,35,39,42,43)$ and the remainder were available in full text. A previous trial had 4 treatment arms (44), among which 3 (EVL alone, EVL plus propranolol plus ISMN and propranolol plus ISMN) were included from the present study. Another had 3 arms (22), of which 2 (EVL alone and propranolol plus ISMN) were included, and the arm of carvedilol treatment alone was excluded. All of the other trials were designed with 2 treatment arms. The proportion of patients with cirrhosis was $100 \%$ in all of the trials. The baseline characteristics of the trials are presented in Table I. 


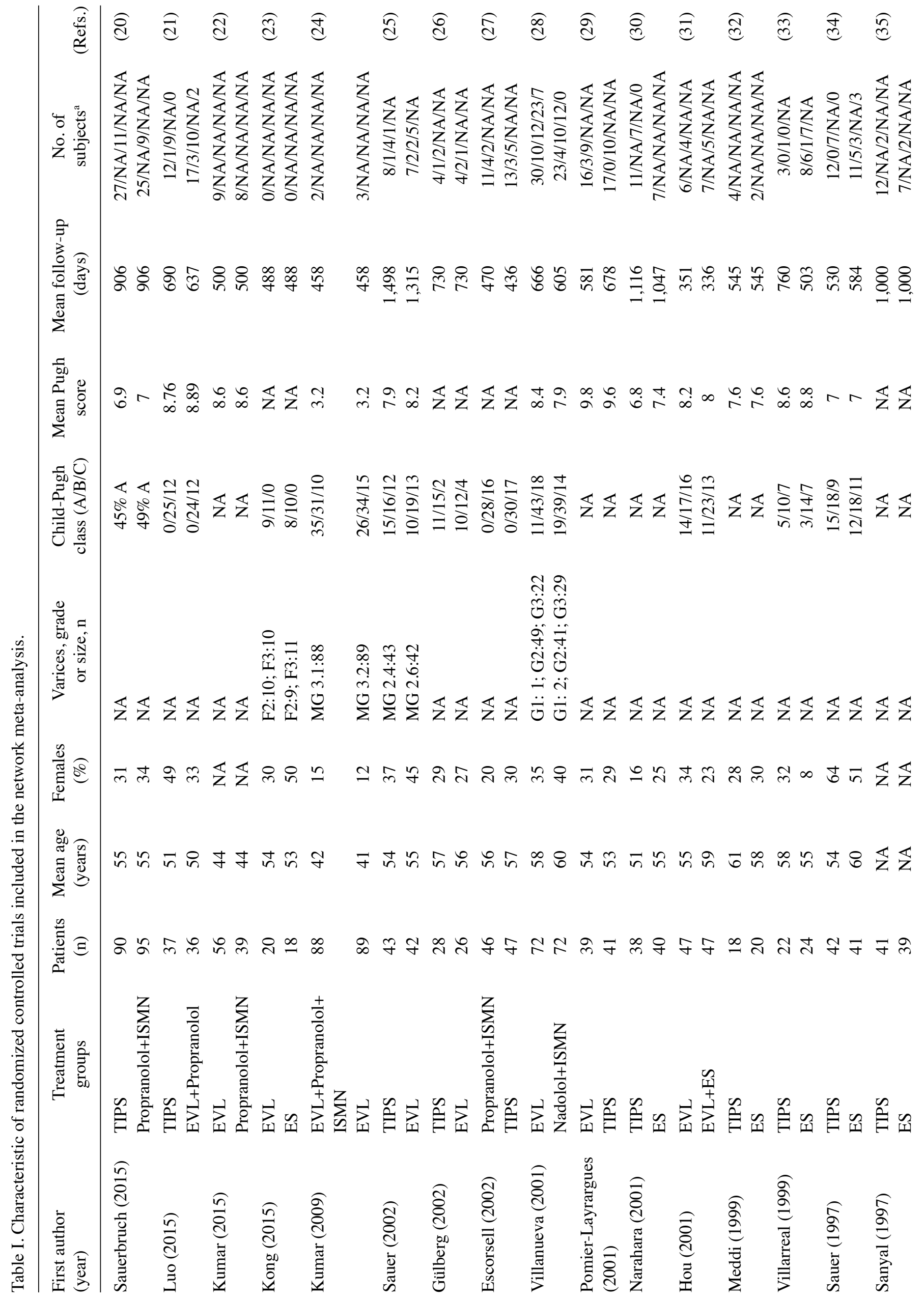


离

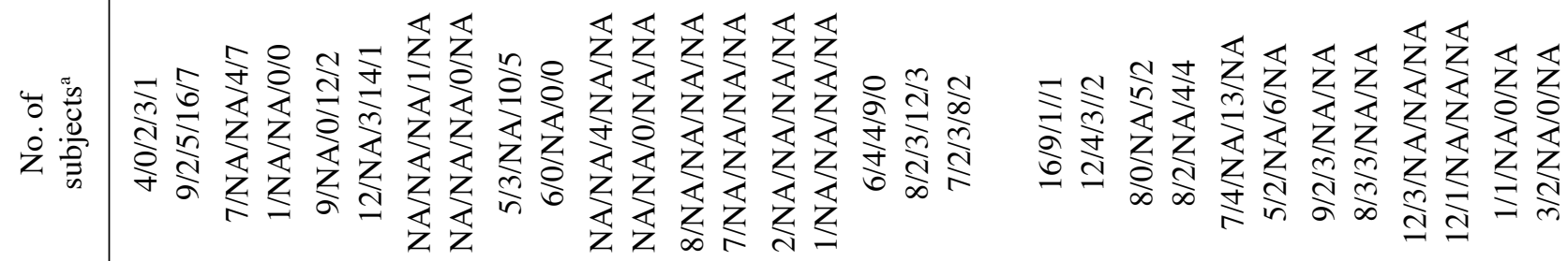
产

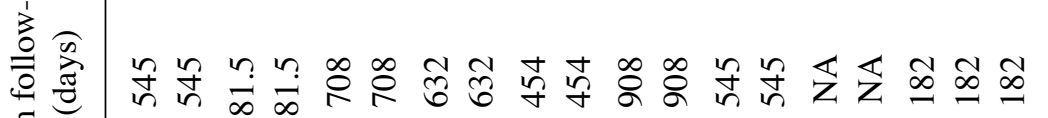
离

密

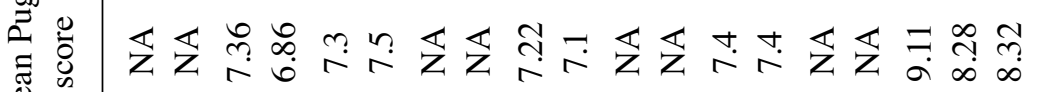
$\sum^{ \pm}$

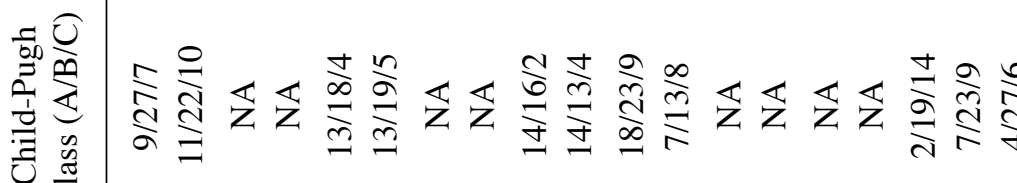

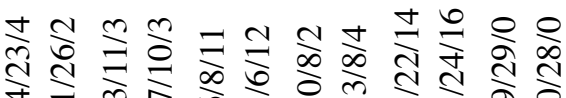

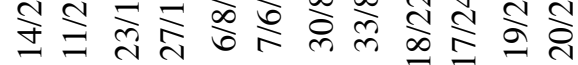

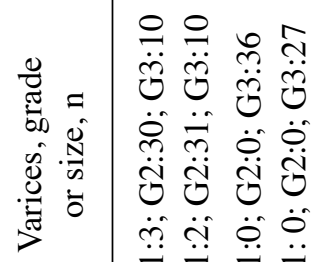

导

$\ddot{n} \ddot{\mathrm{m}}$

ชิ

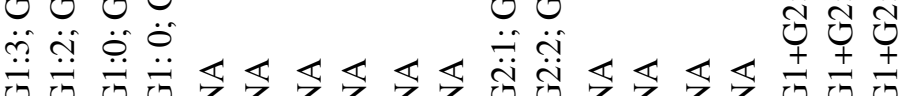

4. $\ddot{O} \ddot{O} \ddot{O}$ $\ddot{\sim} \ddot{n} \ddot{n}$ نิ่

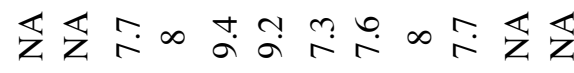

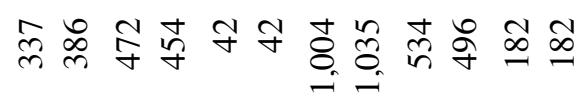

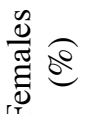
要

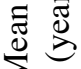

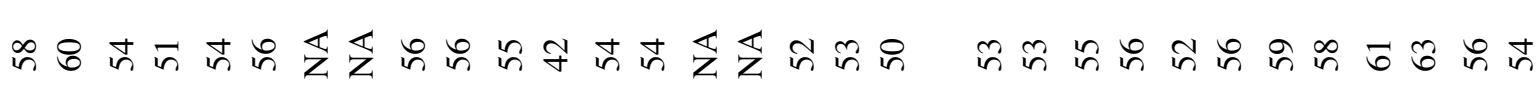
产

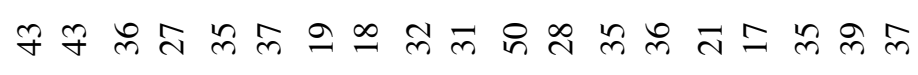

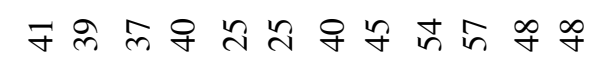

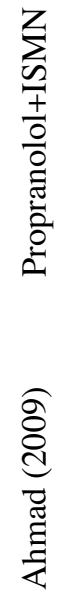

9. 으

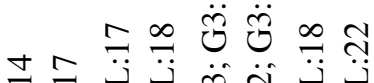
$\ddot{\ddot{v}} \ddot{\ddot{\theta}}$

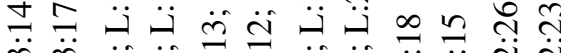

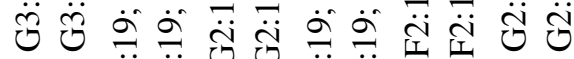

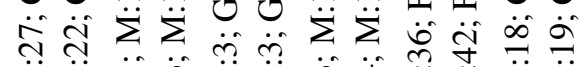

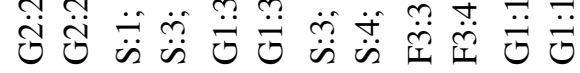

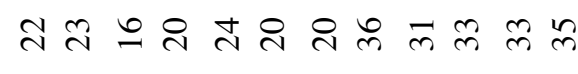




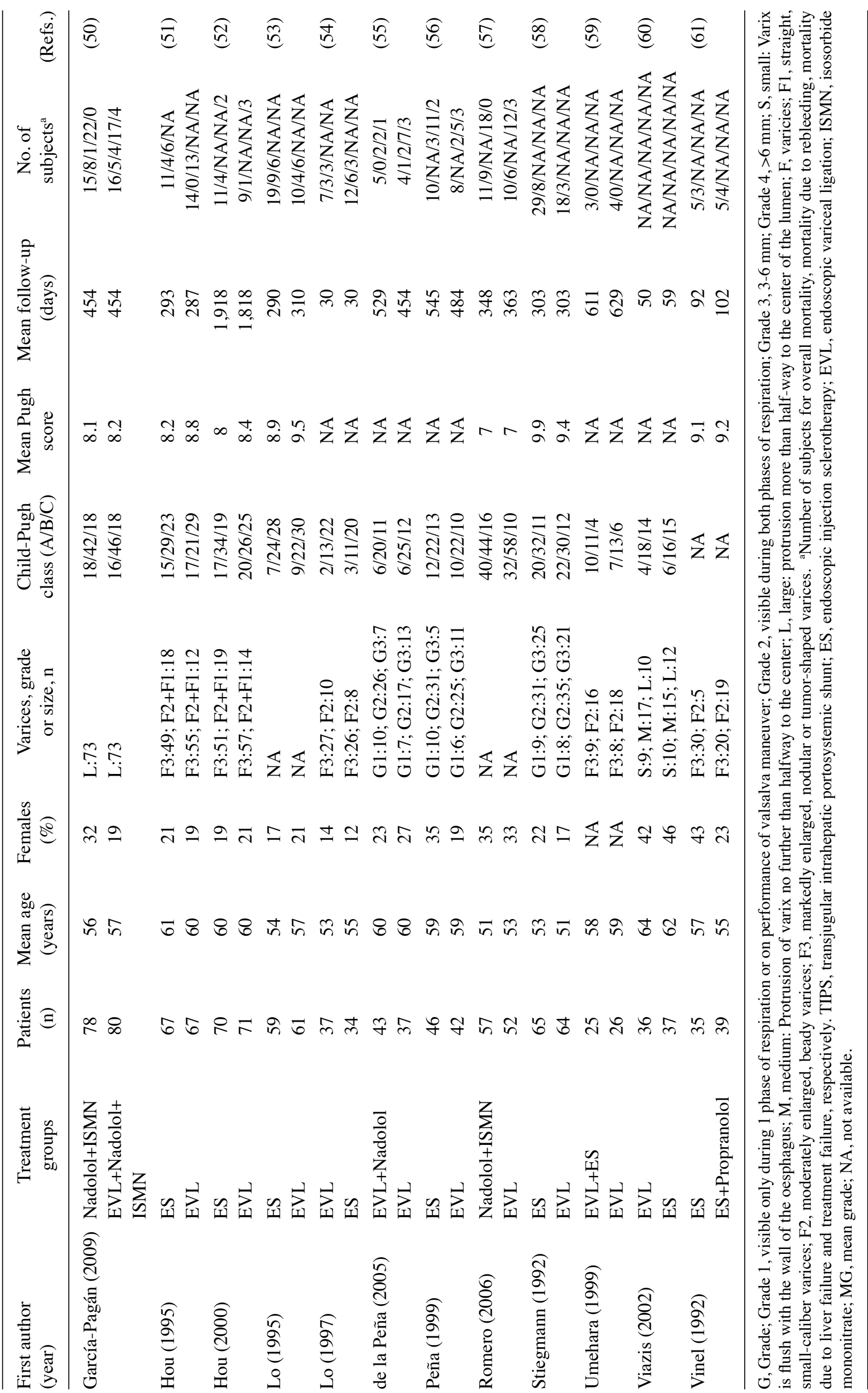


Patient inclusion and exclusion criteria varied slightly across trials, but patients were generally eligible if they were adults with cirrhosis with at least one episode of endoscopic-proven oesophageal or gastric variceal bleeding. Exclusion criteria included hepatocarcinoma, non-bleeding varices, existing multi-organ failure and lack of cirrhosis. A total of 30 of the 43 studies had a mean follow-up time of $>2$ years, as presented in Table I. In total, five trials were excluded from the sensitivity analysis due to follow-up times that were unknown or $<6$ months $(43,47,55,60,61)$. TIPS alone was used as the comparative treatment in the forest plots, since it is a recommended surgery for secondary prophylaxis according to the newest UK guidelines (5).

Bias assessment. Risk of bias assessment for the RCTs included was performed following the PRISMA recommendations; the results are presented in Table SI. A total of 26 (61\%) trials (20-22, 24-30,34,36,38,44,47,16,50,56,61) adopted concealed randomization via sealed opaque envelopes, by using central randomization or through an independent person not involved in the treatment of the patients. Only one trial declared early cessation (54). A total of two trials were open labelled $(20,24)$ and two trials reported using outcome assessors under blinded conditions $(27,16)$. Blinding of the remaining trials was not specified.

Overall mortality. In total, 40 trials with a total of 3,599 patients reported overall mortality, involving all 11 treatment regimens. Fig. S1A illustrates the evidence networks connecting the regimens. Nadolol plus ISMN also had the highest P-score $(\mathrm{P}$-score $=0.8162$, Table II) with the largest probability to reduce mortality when compared with the other treatments. No statistical heterogeneity was observed (Heterogeneity $\mathrm{I}^{2}=0 \%$; Cochran's test $\mathrm{P}=0.9618$, Table III) in this outcome measure. The fixed-effects model analysis suggested that nadolol plus ISMN was significantly more effective than TIPS alone (OR=0.62, 95\% CI: 0.40-0.96, Table III), as presented in Fig. 2A. Pairwise comparisons indicated that nadolol plus ISMN and EVL alone were significantly more effective than ES alone in reducing overall mortality $(\mathrm{OR}=0.63,95 \% \mathrm{CI}$ : $0.42-0.94$; $\mathrm{OR}=0.80$, 95\% CI: 0.65-0.99, respectively, Table III), while differences among other treatments were not statistically significant.

Mortality due to rebleeding. A total of 27 trials with 2,447 patients investigated all 11 treatments and reported death due to rebleeding. The evidence network presented in Fig. S1B connects all of the treatments. Cochran's Q test did not identify any statistical heterogeneity among the selected trials for this outcome measure (Heterogeneity $\mathrm{I}^{2}=0, \mathrm{P}=0.9963$, Table III). Compared with TIPS alone, ES plus propranolol increased the risk of mortality due to rebleeding $(\mathrm{OR}=10.39,95 \% \mathrm{CI}$ : 2.24-48.26, Fig. 2B; P-score=0.0842; Table II).

Pairwise comparisons indicated that ES plus EVL, EVL alone, EVL combined with nadolol plus ISMN, Nadolol plus ISMN, Propranolol plus ISMN and TIPS alone were significantly more effective than ES alone in reducing mortality due to rebleeding $(\mathrm{OR}=0.23,95 \% \mathrm{CI}$ : $0.08-0.69 ; \mathrm{OR}=0.37,95 \%$ CI: $0.21-0.63 ; \mathrm{OR}=0.18,95 \%$ CI: $0.04-0.70 ; \mathrm{OR}=0.29,95 \%$ CI: $0.12-0.69$; OR=0.17, 95\% CI: 0.04-0.77; OR=0.12, 95\% CI: 0.04-0.35, respectively, Table III).
Mortality due to liver failure. A total of 24 trials with 2,258 patients investigating all 11 treatments reported on death due to liver failure. The evidence network presented in Fig. S1C connects all of the treatments. No statistical heterogeneity was observed (Heterogeneity $\mathrm{I}^{2}=0 \%, \mathrm{P}=0.8985$; Table III). The results of the fixed-effects model analysis comparing with TIPS alone indicated that none of the other treatments were superior, though nadolol plus ISMN may be the next best option (OR=0.51, 95\% CI: 0.22-1.20, Fig. 2C; P-score=0.7536; Table II). Furthermore, EVL combined with nadolol plus ISMN had the lowest P-score (P-score $=0.2167$, Table II), indicating the highest probability to increase mortality due to liver failure. Results of pairwise comparisons indicated no statistically significant differences when comparing with treatments other than TIPS (Table III).

Treatment failure. In total, 14 trials with a total of 1,445 patients reported on treatment failure. No data of this outcome were available for the treatment regimen ES plus propranolol. The evidence network in Fig. S1B connects the other 10 treatments for assessment of this outcome. Mild heterogeneity was identified for treatment failure (Heterogeneity $\mathrm{I}^{2}=29.4 \%$, $\mathrm{P}=0.1739$; Table III). A fixed-effects model analysis was performed for comparing with TIPS alone. Differences were not statistically significant (Fig. 2D). The evidence network presented in Fig. S1D connects all of the treatments. EVL plus propranolol had the highest efficacy $(\mathrm{P}$-score $=0.8071)$, closely followed by TIPS (P-score $=0.7938)$ and EVL plus nadolol $(\mathrm{P}$-score $=0.7932) . \mathrm{ES}$ alone ranked last $(\mathrm{P}$-score $=0.0199)$, suggesting that it was most likely to have the highest rate of treatment failure. Rankings are presented in Table II.

Pooled ORs suggested that ES alone was disadvantageous compared with the other 9 treatments with regard to treatment failure $(\mathrm{OR}=3.72,95 \% \mathrm{CI}: 1.30-10.67$ compared with ES plus EVL; OR=2.13, 95\% CI: 1.31-3.45 compared with EVL alone; $\mathrm{OR}=8.65,95 \% \mathrm{CI}: 1.77-42.15$ compared with EVL plus nadolol; OR=3.69, 95\% CI: 1.65-8.27 compared with EVL plus nadolol plus ISMN; OR=9.09, 95\% CI: 2.08-39.68 compared with EVL plus propranolol; $\mathrm{OR}=3.02$, 95\% CI: 1.22-7.53 compared with EVL plus propranolol plus ISMN; OR=2.78, 95\% CI: 1.54-5.02 compared with nadolol plus ISMN; OR=2.54, 95\% CI: 1.06-6.12 compared with propranolol plus ISMN; OR=8.24, 95\% CI: $2.16-31.40$ compared with TIPS alone; Table III).

Bleeding from gastroesophageal ulcer. A total of 24 trials with a total of 2,258 patients investigated all 11 treatments and reported death due to bleeding from gastroesophageal ulcer. The evidence network is presented in Fig. S1E. There was no statistically significant heterogeneity for this outcome measure (Heterogeneity $\mathrm{I}^{2}=0, \mathrm{P}=0.8354$; Table III). Results of the fixed-effects model analysis performed in comparison with TIPS alone indicated that none of the other 10 treatments were superior, but nadolol plus ISMN appeared to be the best among the compared treatments $(\mathrm{OR}=0.85,95 \%$ CI: 0.09-8.18, Fig. 2E; P-score $=0.7536$, Table II).

Nadolol plus ISMN had the highest P-score $(\mathrm{P}$-score $=0.7536)$, indicating that it had the highest probability of reducing mortality due to rebleeding, followed 


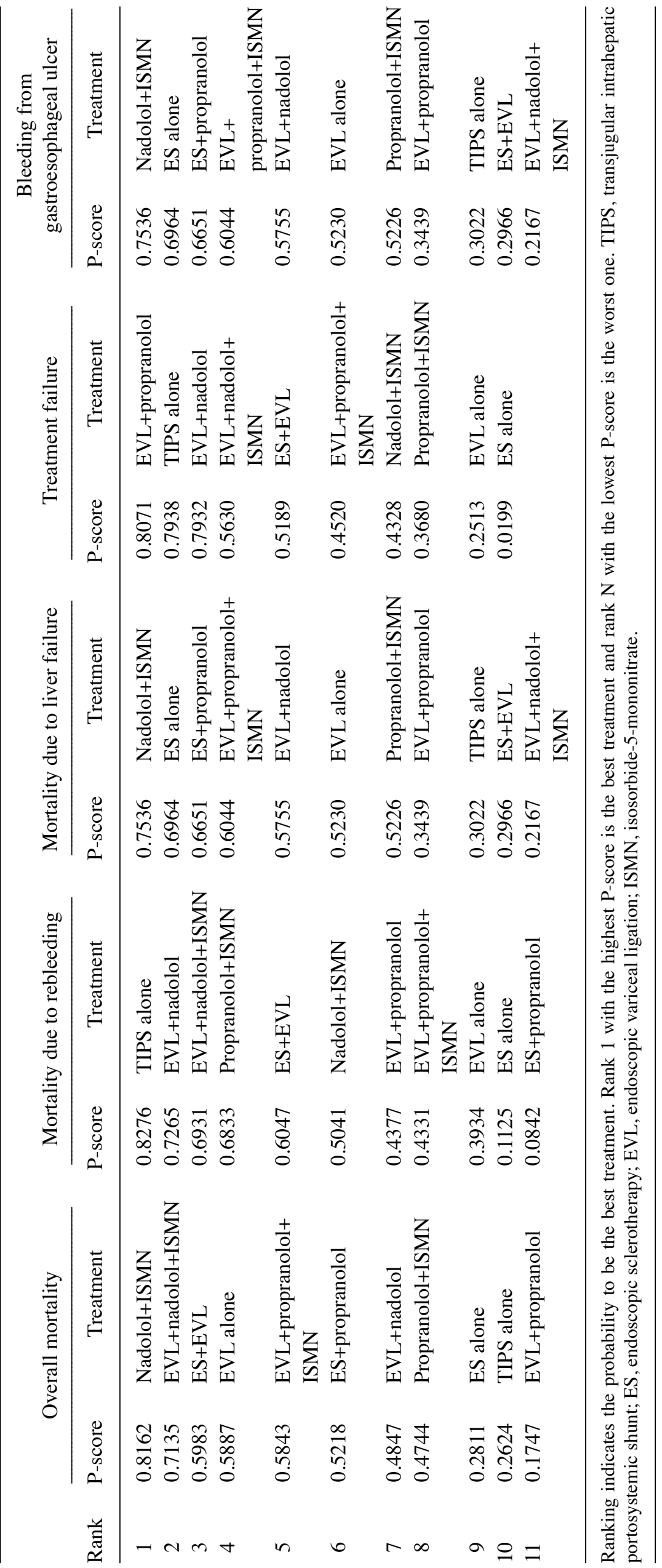




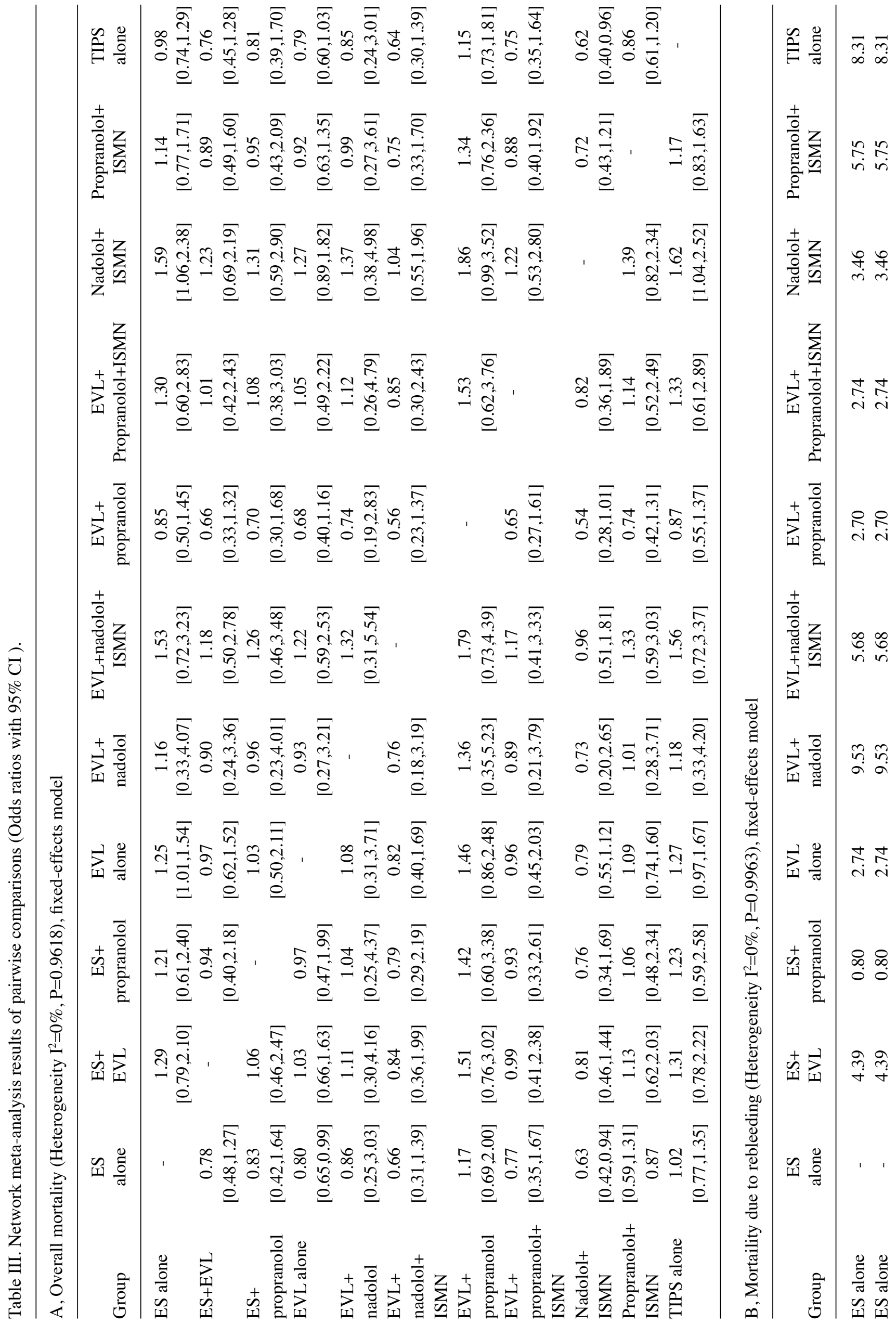




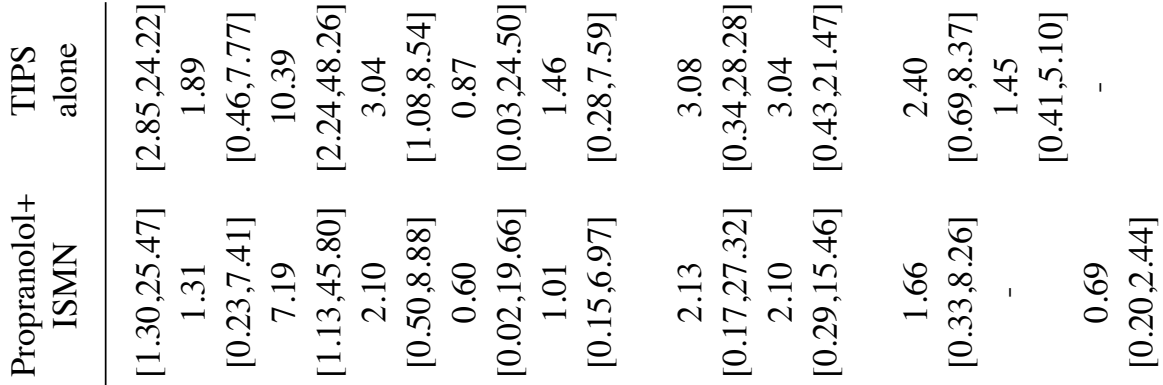

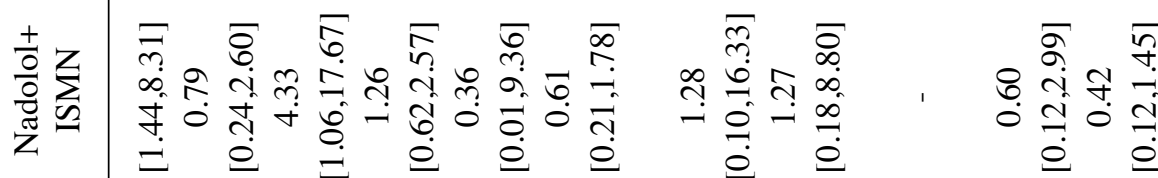

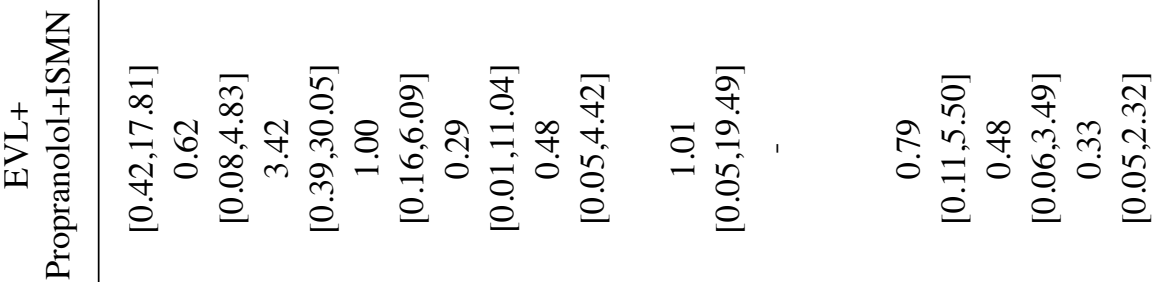

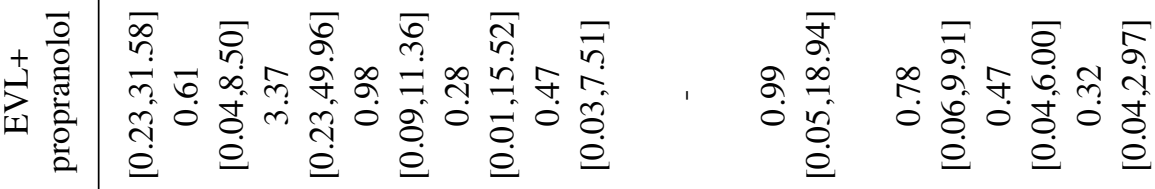

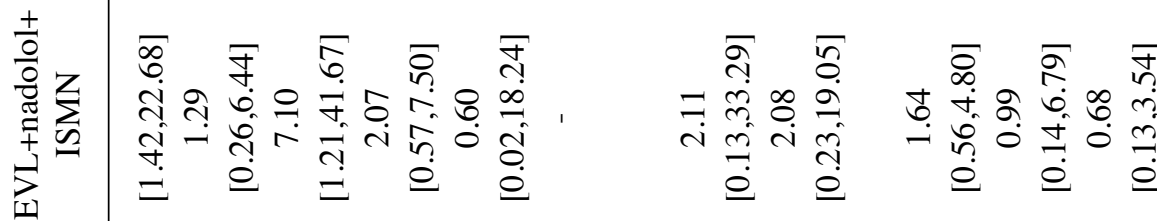

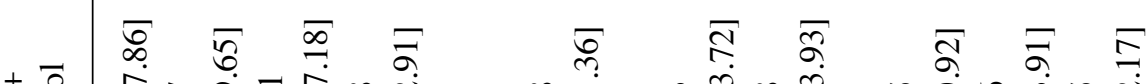

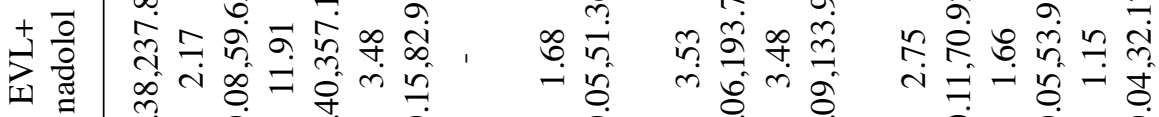

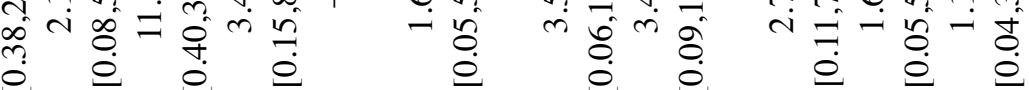

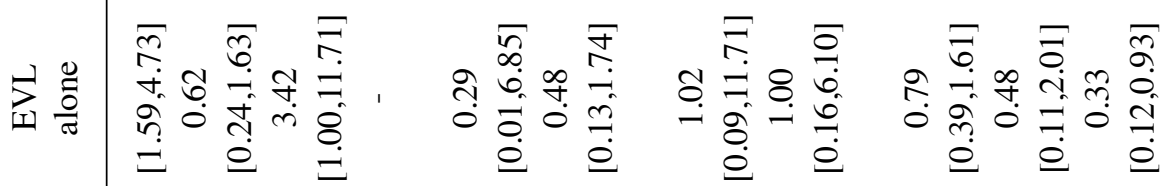

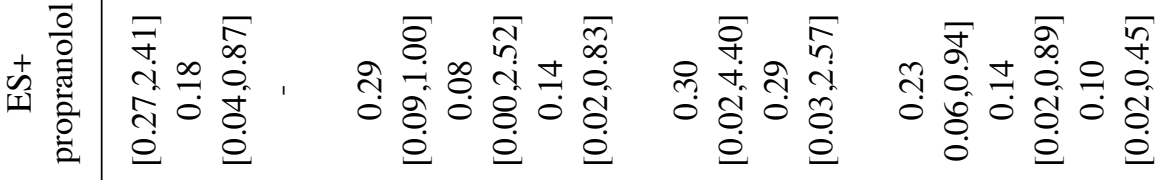

兽

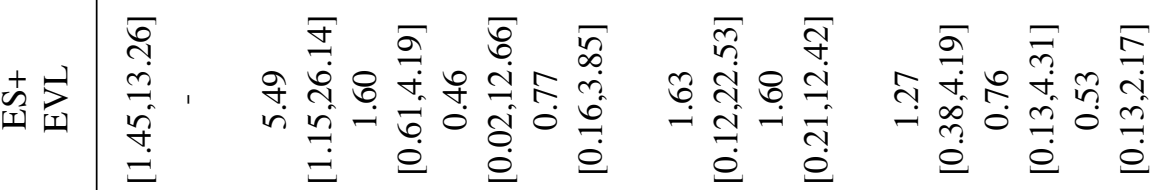

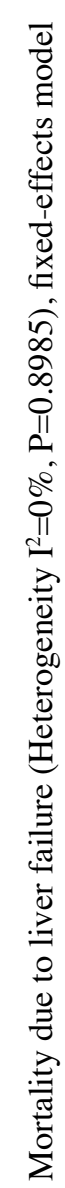

\begin{tabular}{|c|c|c|c|}
\hline$\stackrel{\varrho}{\tilde{E}} \frac{\tilde{\sigma}}{\sigma}$ & 恣 & 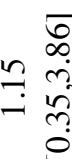 & nc \\
\hline 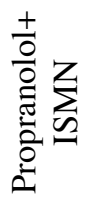 & 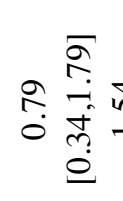 & & {$\left[\begin{array}{ll}\bar{c} \\
0 \\
0 & \bar{a} \\
0 & \bar{c}\end{array}\right.$} \\
\hline 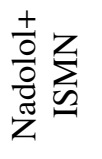 & 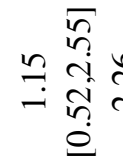 & 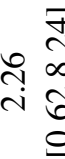 & ฮิ \\
\hline 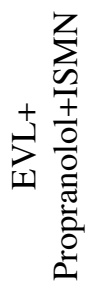 & 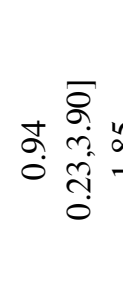 & & 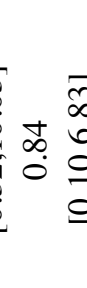 \\
\hline 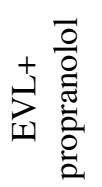 & 兑 & & กี \\
\hline 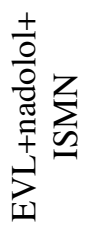 & 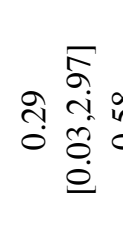 & 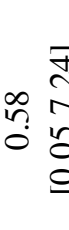 & 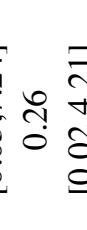 \\
\hline$\sum_{\text {省 }}^{+\frac{0}{0}}$ & 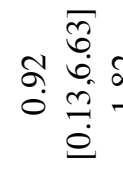 & 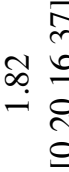 & $\left\{\begin{array}{l}\infty \\
\infty \\
0\end{array}\right.$ \\
\hline$\underbrace{\stackrel{0}{\sigma}}_{\text {兊 }}$ & 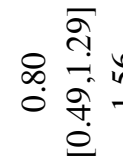 & 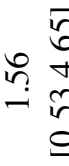 & $\bar{a}$ \\
\hline 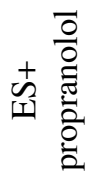 & 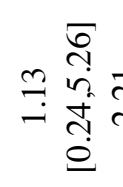 & 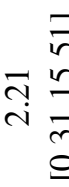 & \\
\hline$\stackrel{+}{\stackrel{4}{\Delta}}$ & 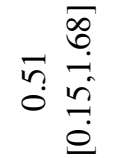 & & $\stackrel{n}{\circ}$ \\
\hline$\Xi$ & 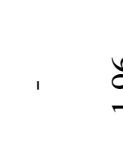 & 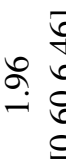 & {$\left[\begin{array}{l}\infty \\
0 \\
0\end{array}\right.$} \\
\hline 言 & $\begin{array}{l}\tilde{\Xi} \\
\tilde{\sigma} \\
\tilde{\omega} \\
\text { II }\end{array}$ & 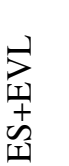 & 芴 \\
\hline
\end{tabular}

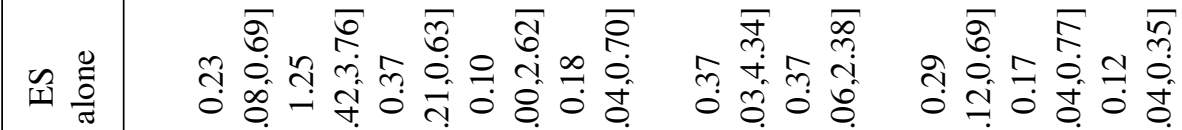
$0 \quad 0 \quad 0 \quad 0 \quad 0 \quad 0 \quad 0 \quad 0 \quad 0 \quad 0$

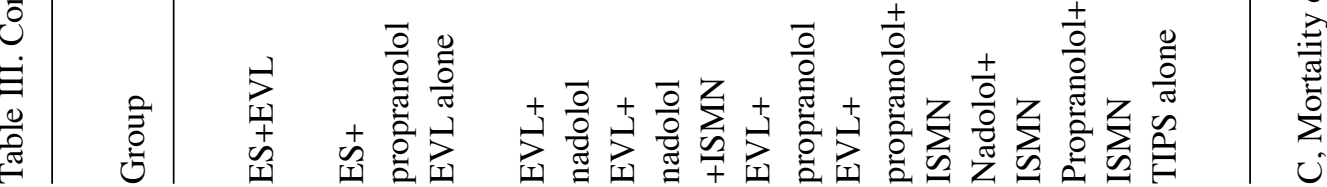




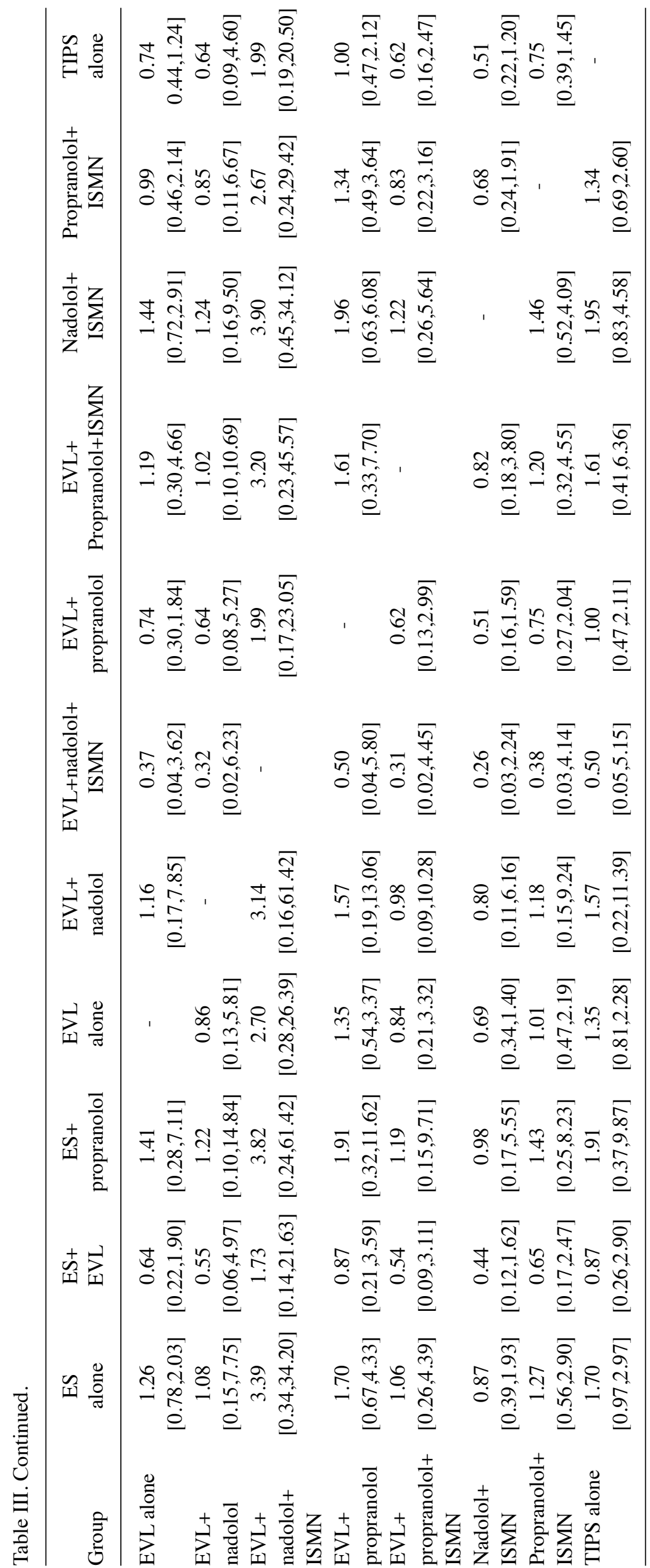

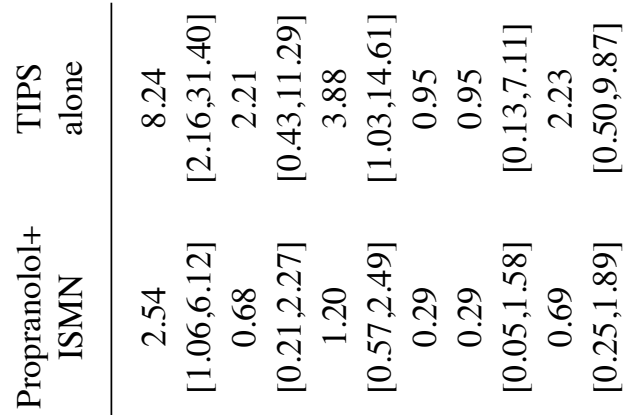

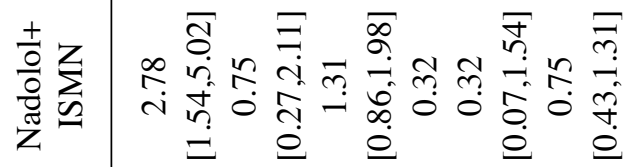

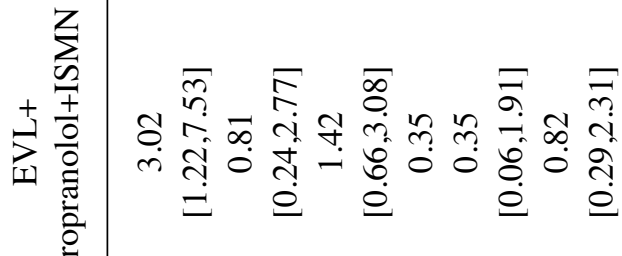

D

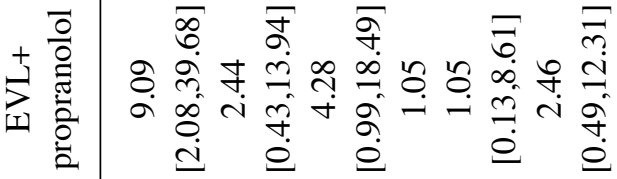

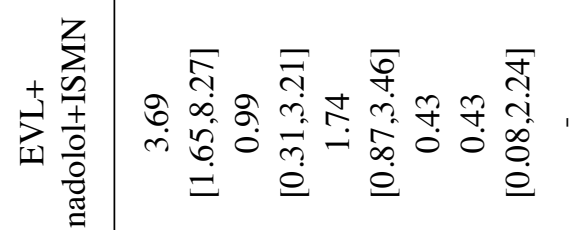

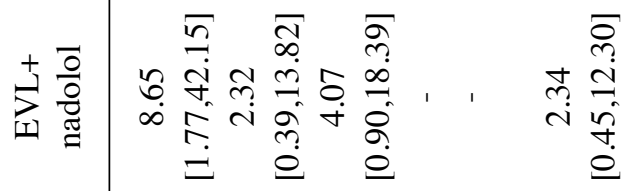

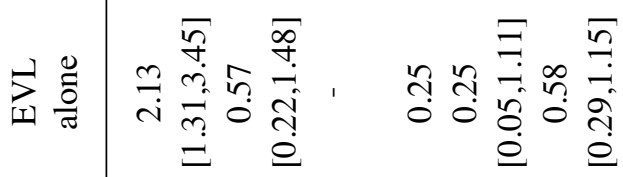

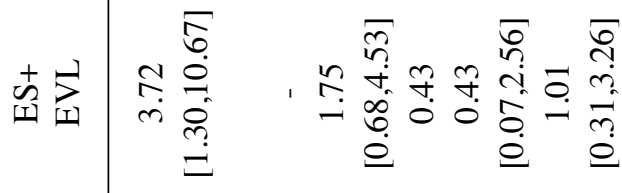

- 듐ำ

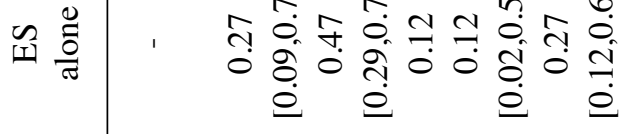

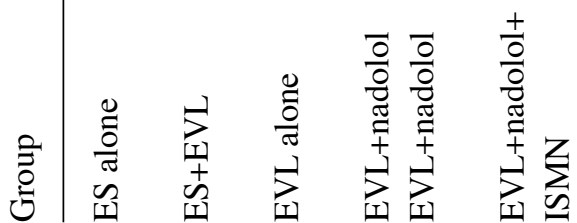




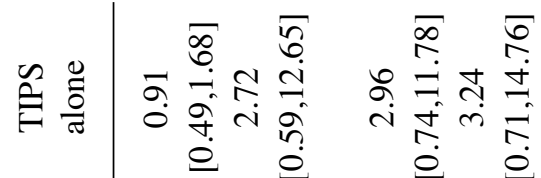

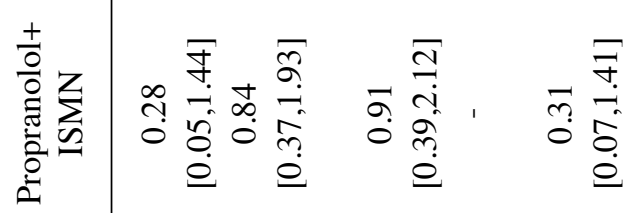

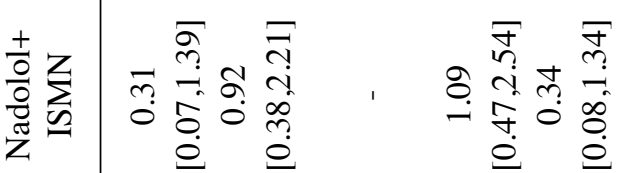

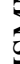

$+$

空

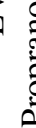

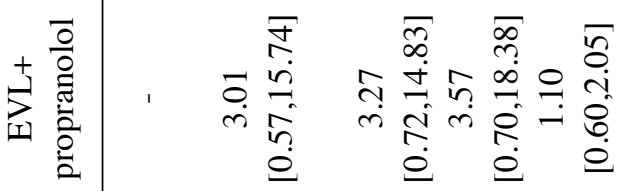

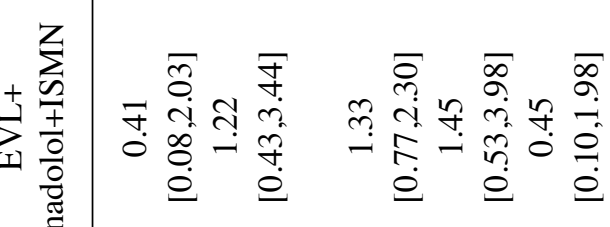

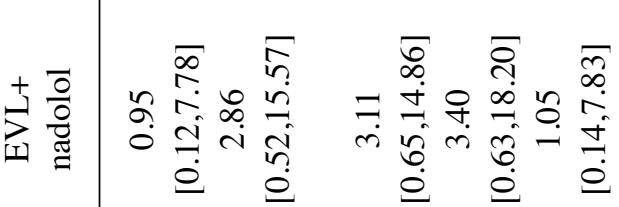

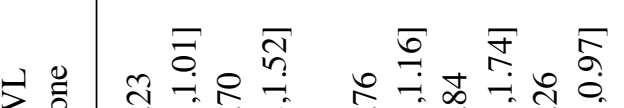

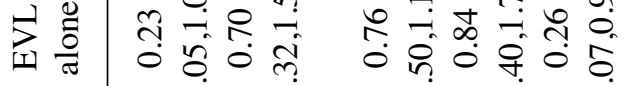

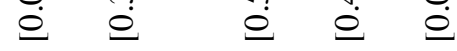

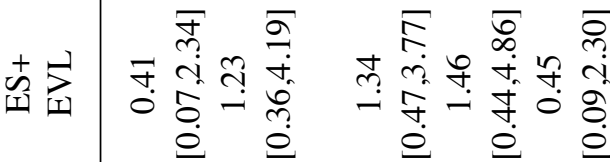

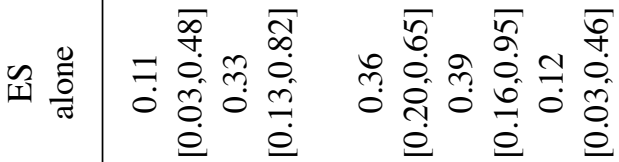

ठำ

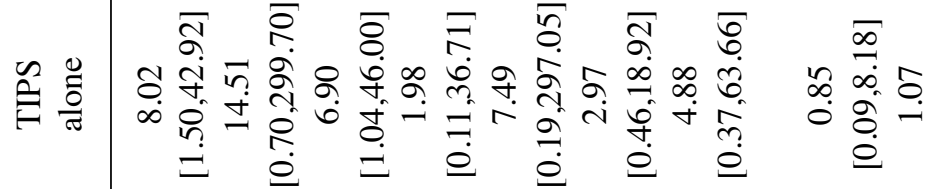

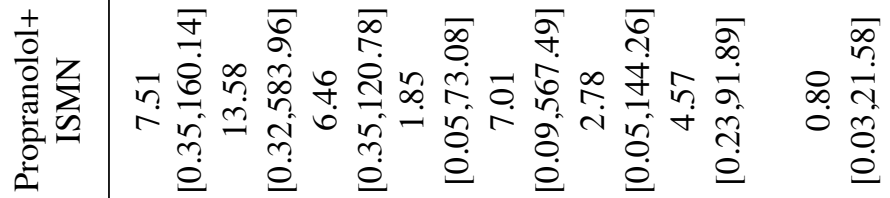

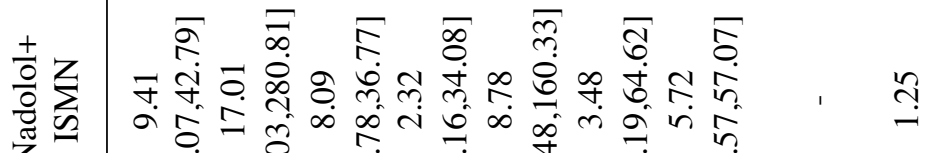

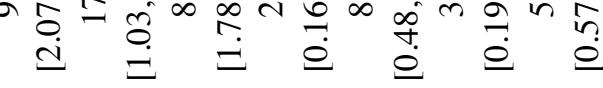

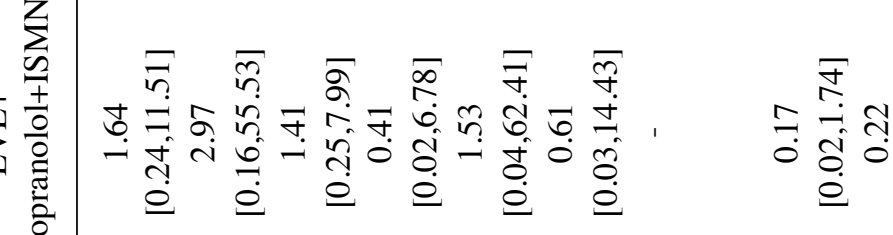

:

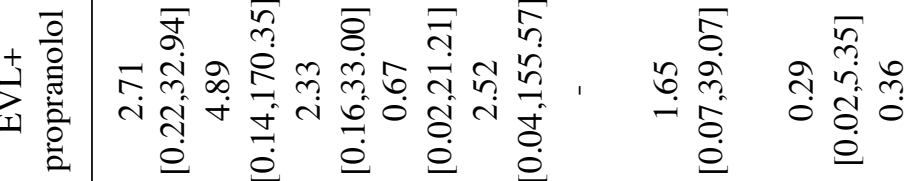

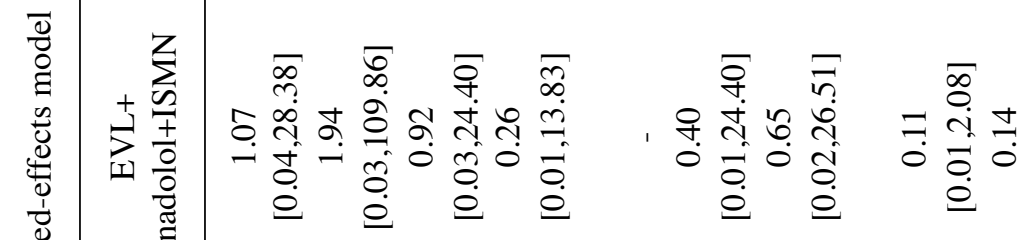

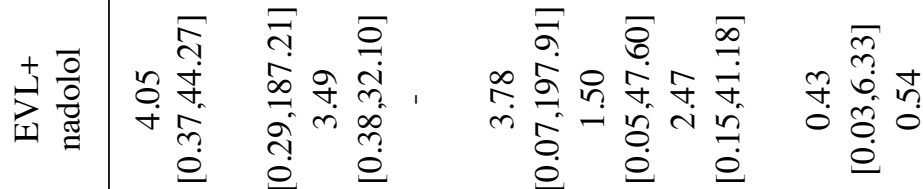

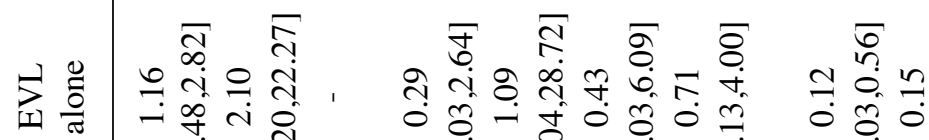

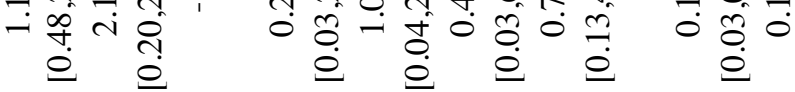

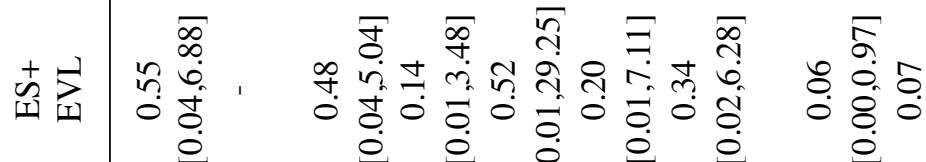
도 윯

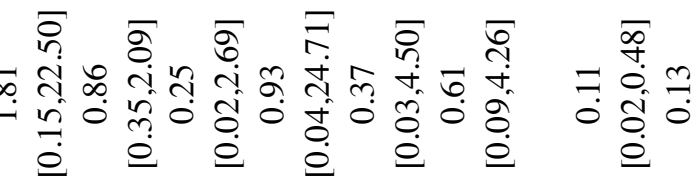

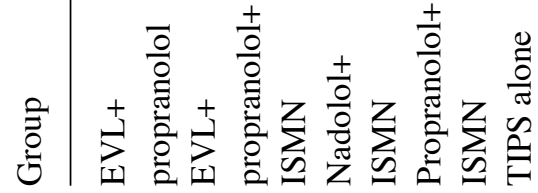

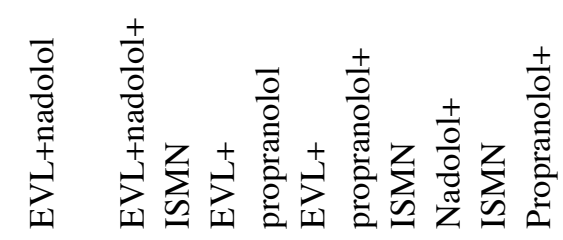


closely by ES alone (P-score $=0.6964)$ and ES plus propranolol $(\mathrm{P}$-score $=0.6651)$. The lowest $\mathrm{P}$-score was obtained for EVL plus nadolol and ISMN (P-score $=0.2167$ ), indicating the lowest probability to reduce bleeding from gastroesophageal ulcer (Table II).

Pairwise comparisons among the treatments indicated that nadolol plus ISMN was associated with a relatively lower risk of causing bleeding from gastroesophageal ulcer when compared with ES alone (OR=0.11, 95\% CI: 0.02-0.48), ES plus EVL $(\mathrm{OR}=0.06,95 \% \mathrm{CI}=0.00-0.97)$ or $\mathrm{EVL}$ alone $(\mathrm{OR}=0.12,95 \%$ CI: 0.03-0.56) in Table III.

Sensitivity analysis. A sensitivity analysis was performed by removing several studies. The only criterion for removal was a mean follow-up time of $<6$ months, based on which 5 trials $(43,47,55,60,61)$ were removed. The results were consistent with those of the primary meta-analysis (Table IV). Nadolol plus ISMN was still superior to TIPS with regard to overall mortality (OR=0.63, 95\% CI: 0.40-0.98, Fig. 3A; Heterogeneity $\mathrm{I}^{2}=0, \mathrm{P}=0.9249$, Table IV), while no significant differences were obtained for treatment failure $(\mathrm{OR}=2.97,95 \%$ CI: $0.74-11.88$, Fig. 3B; Heterogeneity $\mathrm{I}^{2}=37.3 \%, \mathrm{P}=0.1206$, Table IV).

\section{Discussion}

The present network meta-analysis included 43 randomized controlled trials to compare the treatment effectiveness of 11 mainstay secondary prophylaxes in patients with cirrhosis in terms of mortality, treatment failure and bleeding from gastroesophageal ulcers. The results suggested that nadolol plus ISMN was most likely to reduce the risk of overall mortality, mortality due to liver failure and bleeding from gastroesophageal ulcers, and was superior to ES and TIPS alone for reducing overall mortality. ES was inferior to 9 treatments for reducing treatment failure. The combination of endoscopic therapy and NSBB with or without ISMN was not significantly more effective than EVL or the drug combination alone.

The present study included 4 trials that investigated nadolol plus ISMN $(26,36,51,57)$ with a total of 250 randomized patients. Nadolol plus ISMN was indicated to be more effective than TIPS alone in reducing overall mortality. The present results are consistent with those of Villanueva et al (28), which concluded that combination therapy was more effective than endoscopic ligation for the prevention of recurrent bleeding and was associated with lower rates of major complications. As a vasoconstrictor, nadolol is able to reduce portal pressure and blood flow in the porto-collateral system. The vasodilator ISMN has been demonstrated to decrease portal pressure in patients with cirrhosis by reducing intra-hepatic resistance (29). Despite adverse drug-associated effects, including hypotension, asthenia and headaches, proper dosage of this combination is most likely to reduce mortality and other complications of bleeding from ulcers.

In the newly published AASLD and UK guidelines, TIPS is recommended as a treatment option when endoscopic and pharmacologic treatments have failed (5). In the present study, a total of 16 trials provided data for TIPS in 590 patients with cirrhosis $(20,21,25-27,29,30,32-35,38-40,42,43)$. The mean follow-up time for TIPS groups was 748.5 days [data for one 
A Comparison to TIPS Alone Fixed Effect Model

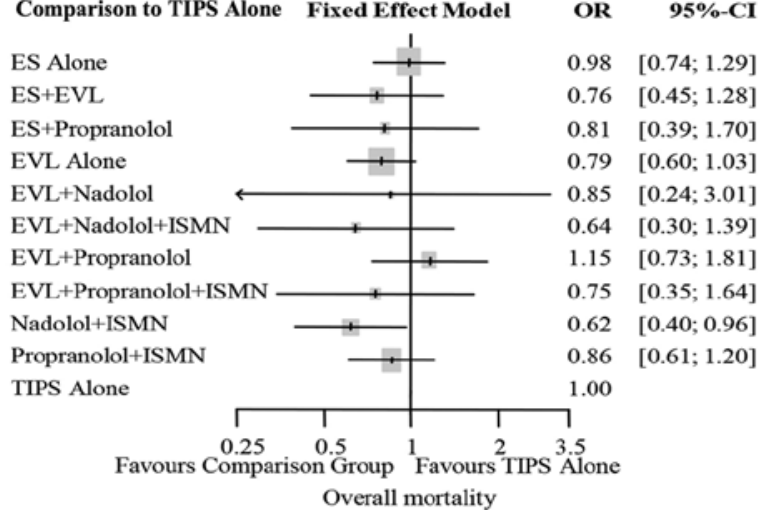

C Comparison to TIPS Alone Fixed Effect Model

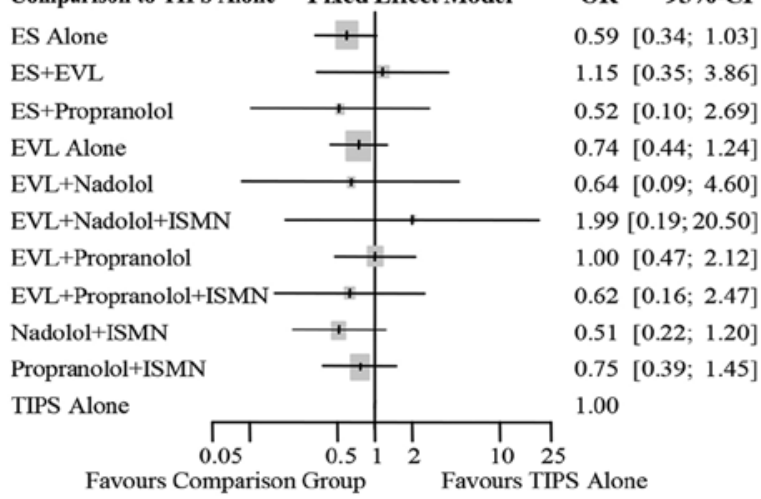

Mortality due to liver failure
B Comparison to TIPS Alone Fixed Effect Model $\quad$ OR $\quad 95 \%$-CI \begin{tabular}{l|l} 
ES Alone & $\longrightarrow$ \\
\hline & $8.31[2.85 ; 24.22]$
\end{tabular} ES+EVL $\quad \longrightarrow \quad 1.89[0.46 ; 7.77]$ ES+Propranolol $\quad \longrightarrow 10.39[2.24 ; 48.26]$

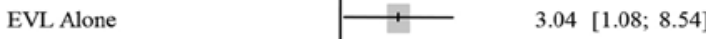
\begin{tabular}{l|l} 
EVL+Nadolol $\longleftarrow 0.87[0.03 ; 24.50]$ \\
$\quad \longleftarrow$
\end{tabular} EVL+Nadolol+ISMN $\longrightarrow \frac{1}{\longrightarrow} 1.46[0.28 ; 7.59]$ EVL+Propranolol $\quad \longrightarrow$ - $3.08[0.34 ; 28.28]$ $\begin{array}{lll}\text { EVL+Propranolol+ISMN } & \text { 3.04 [0.43;21.47] }\end{array}$ $\begin{array}{llll}\text { Nadolol+ISMN } & 2.40[0.69 ; 8.37]\end{array}$ \begin{tabular}{lll} 
Propranolol+ISMN & \multicolumn{1}{|l}{$\begin{array}{l}1.45[0.41 ; 5.10] \\
\text { TIPS Alone }\end{array}$} & 1.00
\end{tabular}

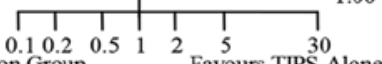

Favours Comparison Group 12 Favours TIPS Alone

Mortality due to rebleeding

D Comparison to TIPS Alone Fixed Effect Model $\quad$ OR $\quad 95 \%-C I$

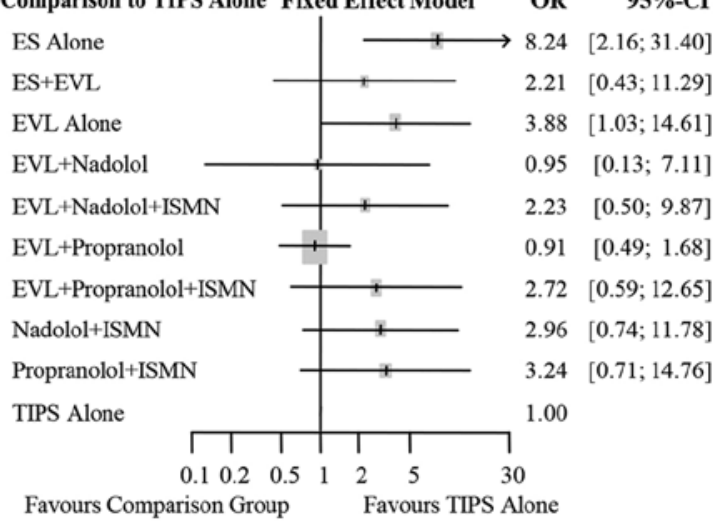

Treatment failure

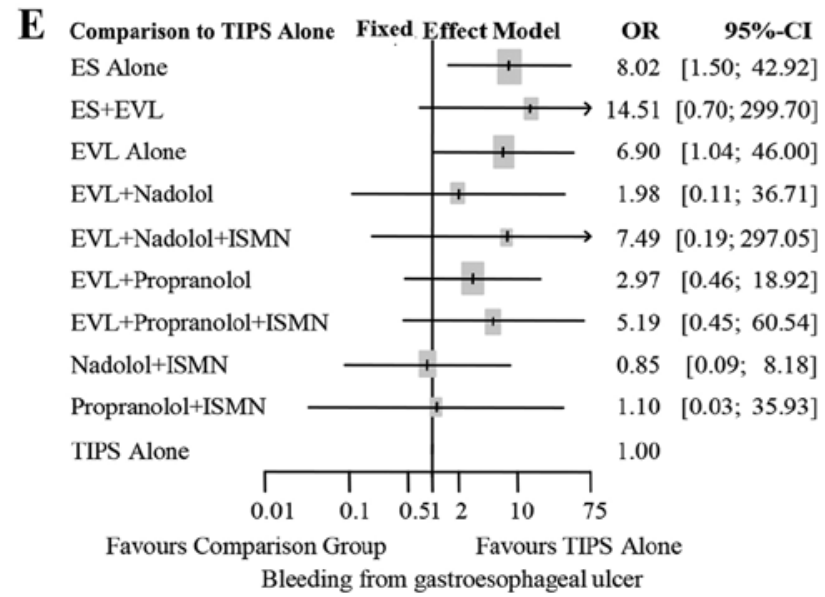

E Comparison to TIPS Alone Fixed Effect Model OR $\quad 95 \%$-CI

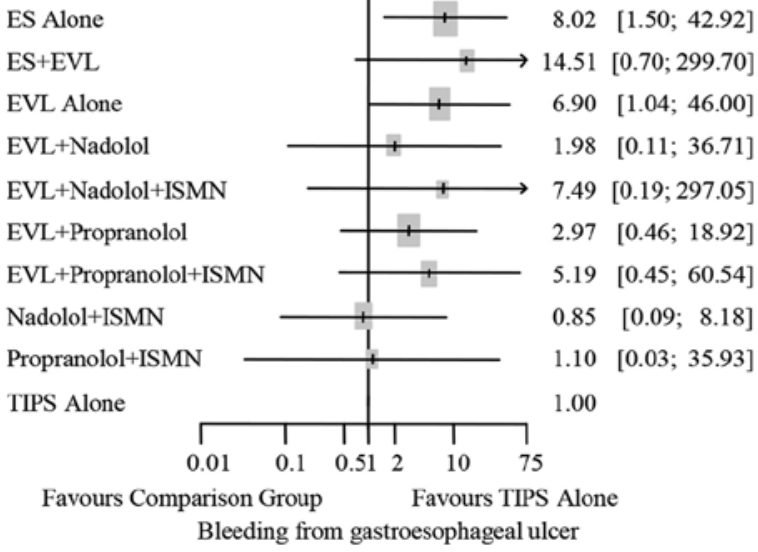

Figure 2. Forest plots with different pairwise comparisons with TIPS alone in network meta-analyses for (A) overall mortality, (B) mortality due to rebleeding, (C) mortality due to liver failure, (D) treatment failure and (E) bleeding from gastroesophageal ulcer. TIPS, transjugular intrahepatic portosystemic shunt; OR, odds ratio; ES, endoscopic sclerotherapy; EVL, endoscopic variceal ligation; ISMN, isosorbide mononitrate.

trial (43) were not available]. Although TIPS is known to have the potential to increase hepatic encephalopathy $(20,27)$, the present study demonstrated that it may reduce the risk of death due to rebleeding. The trials were contradictory regarding whether TIPS is superior to endoscopic or combination therapies. In one previous trial (26), TIPS alone was superior to EVL plus propranolol in the prevention of rebleeding, but this superiority did not result in improved survival. In this previous study (26), liver failure, hepatobiliary cancer and sepsis were the predominant causes of death. Clinically, it may be difficult to attribute death to rebleeding or to any one cause. Zheng et al (62) performed a meta-analysis of 12 RCTs to compare TIPS with endoscopic therapy, and the results suggested that TIPS reduced variceal rebleeding, but was associated with an increased risk of encephalopathy, although no differences in survival were observed. The present study indicated that TIPS was superior to ES alone, ES plus propranolol and EVL alone with a tendency for reduced mortality due to rebleeding. In clinical practice, TIPS has certain advantages in reducing portal pressure and reducing the risk of rebleeding. However, compared with endoscopic treatment, TIPS is more costly and technically more difficult. 
Table IV. Heterogeneity test results.

\begin{tabular}{|c|c|c|c|c|}
\hline Item & $\mathrm{I}^{2}(\%)$ & Q & DF & P-value \\
\hline Overall mortality & 0 & 19.34 & 32 & 0.9618 \\
\hline Overall mortality (sensitivity analysis) & 0 & 18.05 & 28 & 0.9249 \\
\hline Mortality due to rebleeding & 0 & 5.97 & 18 & 0.9963 \\
\hline Treatment failure & 29.4 & 12.76 & 9 & 0.1739 \\
\hline Treatment failure (sensitivity analysis) & 37.3 & 12.75 & 8 & 0.1206 \\
\hline Bleeding from gastroesophageal ulcer & 0 & 4.23 & 8 & 0.8354 \\
\hline Mortality due to liver failure & 0 & 8.58 & 15 & 0.8985 \\
\hline
\end{tabular}

DF, degrees of freedom.

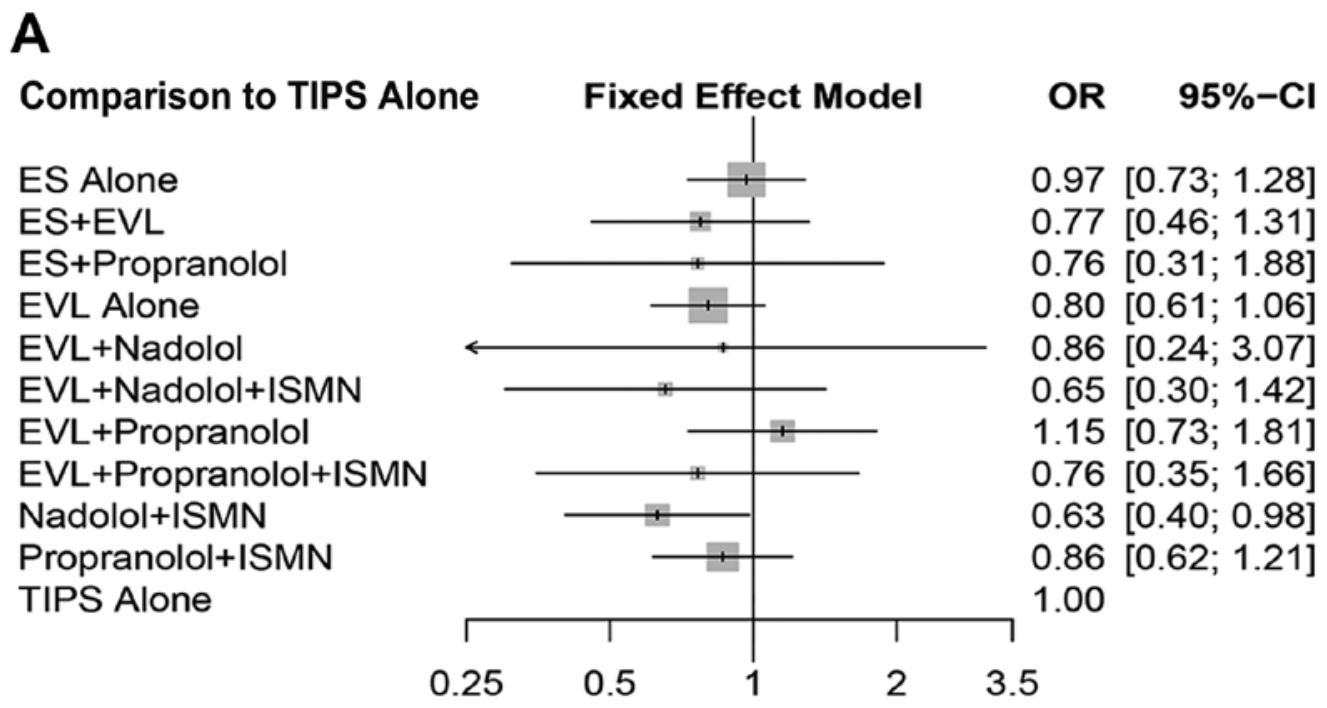

Favours Comparison Group Favours TIPS Alone

Overall mortality

B

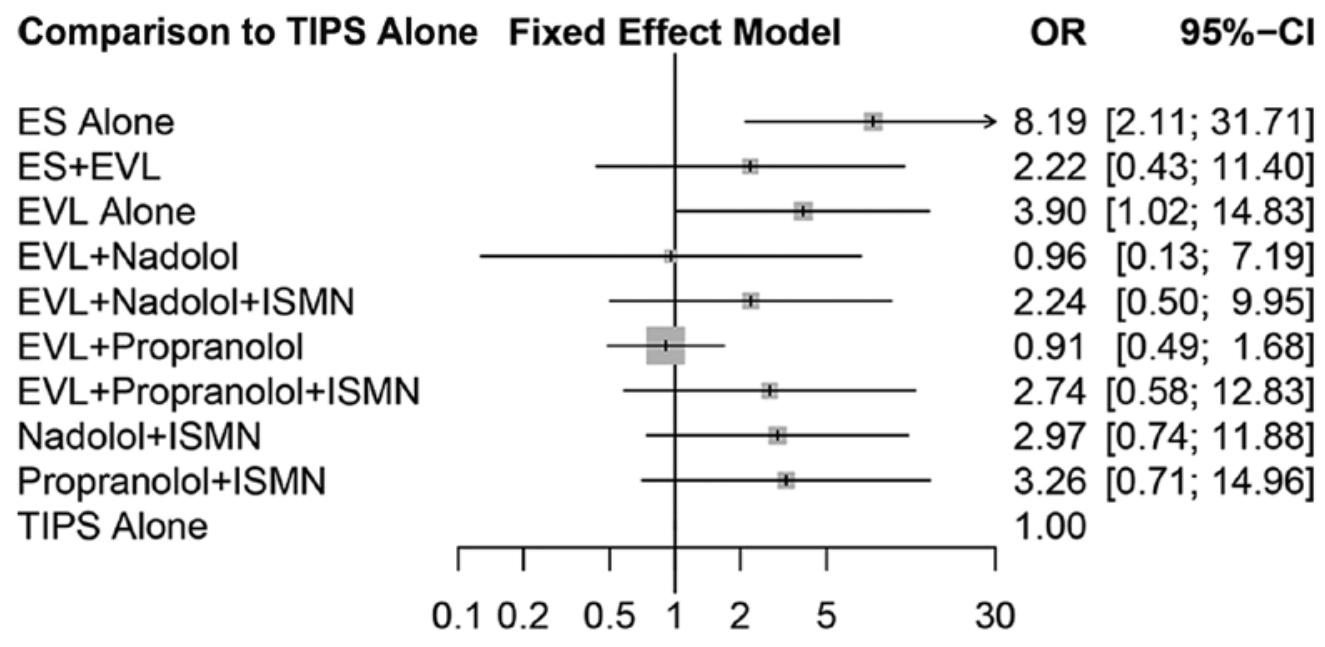

Favours Comparison Group Favours TIPS Alone

Treatment failure

Figure 3. Sensitivity analysis for (A) overall mortality and (B) treatment failure. Trials with a mean follow-up of $<6$ months were removed to generate forest plots for different pairwise comparisons with TIPS alone. TIPS, transjugular intrahepatic portosystemic shunt; OR, odds ratio; ES, endoscopic sclerotherapy; EVL, endoscopic variceal ligation; ISMN, isosorbide mononitrate. 
Data from 4 previous studies $(21,26,27,38)$ that used covered stents in their trials provided similar results among TIPS, EVL, EVL plus propranolol and propranolol plus ISMN in terms of overall mortality, although TIPS appeared to cause less mortality due to rebleeding than EVL plus propranolol (21).

Although ES was not recommended by the Baveno VI Consensus Workshop as a first-line treatment (15), it is still commonly used in China (61). Furthermore, the guidelines of the Chinese Society of Gastroenterology, Chinese Medical Association and Chinese Society of Endoscopy suggest that physicians choose EVL or ES for secondary prophylaxis based on their experience and the patients' clinical conditions (62). Therefore, RCTs on ES were not excluded from the present study.

Results of pooled ORs demonstrated inferiority of ES regarding treatment failure over the other 9 treatments. ES plus propranolol may increase the risk of mortality due to rebleeding. No statistically significant benefit of ES alone or ES plus drugs was identified in the present study. The results of the present study are consistent with those of previous studies $(7-12,15)$ and support the most recent UK and AASLD guidelines, which do not recommend ES for secondary prevention of variceal bleeding in patients with cirrhosis (5).

EVL has been accepted as the preferred endoscopic treatment for the prevention of variceal rebleeding (37). Although EVL plus NSBB is now the first-line treatment, a review by Cotoras et al (64) reported that addition of $\beta$-blockers to EVL does not lead to a difference in mortality. In line with this, in the present study, the combination of EVL and NSBB with or without ISMN was not more effective than EVL alone or the drug combination of NSBB and ISMN.

The present study identified a tendency of EVL plus propranolol to increase mortality, which may be attributed to the data that were extracted from the included trials for this outcome measure. In a previous trial whose patients all had grade II-IV portal vein thrombosis (PVT), Luo et al (21) determined that the ability of EVL plus propranolol to reduce variceal bleeding may be counteracted by deteriorated PVT. Additional evidence from high-quality RCTs is required to address this issue.

The present study has several limitations. Therapy using drugs alone or using drugs other than NSBB or ISMN were beyond the scope of the present study, as regimens of single drugs are now seldom used in clinical practice for secondary prophylaxis. Although the included trials provided a solid foundation based on collected data, more data on serious adverse effects, the frequency and severity of drug-associated adverse effects, procedure-associated complications and consequent hospitalization may be helpful for further comparison. The quality of the present study depends on the RCTs that were included. A total of 4 RCTs focusing on acute variceal bleeding $(37,38,47,54)$ were included, as they also assessed the outcomes of rebleeding and overall mortality. The included references were published between 1992 and 2015, which is a long period of time; there may be technical differences in the early stages; however, with the continuous standardization and maturity of operation technology, the differences are gradually narrowing. Therefore, the clinical value of the present results may be limited.

In conclusion, the present network meta-analysis suggested that for prophylaxis of variceal rebleeding in patients with cirrhosis, nadolol plus ISMN may be the preferred choice to decrease mortality and ES may be associated with a relatively higher risk of unfavourable treatment outcomes, particularly treatment failure.

\section{Acknowledgements}

The authors would like to thank Dr Sam Zhong and Dr Michelle Liu (Shanghai KNOWLANDS MedPharm Consulting Co.,Ltd.) for their support with data analyses in the present study.

\section{Funding}

No funding was received.

\section{Availability of data and materials}

The datasets used and/or analyzed in the present study are availabled from the correspoding author on reasonable request.

\section{Authors' contributions}

YK was responsible for the study design, data collection and analysis and manuscript review. LS reviewed the data collection and analysis and drafted the manuscript. Both authors read and approved the final manuscript.

\section{Ethics approval and consent to participate}

Not applicable.

\section{Patient consent for publication}

Not applicable.

\section{Competing interests}

The authors declare that they have no competing interests.

\section{References}

1. Bresci G: Portal hypertension: The management of esophageal/gastric varices, portal hypertensive gastropathy or hypertensive colopathy. Therapy 4: 91-96, 2007.

2. Mansour L, El-Kalla F, EL-Bassat H, Abd-Elsalam S, El-Bedewy M, Kobtan A, Badawi R and Elhendawy M: Randomized controlled trial of scleroligation versus band ligation alone for eradication of gastroesophageal varices. Gastrointest Endosc 86: 307-315, 2017.

3. Sarin SK, Lahoti D, Saxena SP, Murthy NS and Makwana UK: Prevalence, classification and natural history of gastric varices: A long-term follow-up study in 568 portal hypertension patients. Hepatology 16: 1343-1349, 1992.

4. Trudeau W and Prindiville T: Endoscopic injection sclerosis in bleeding gastric varices. Gastrointest Endosc 32: 264-268, 1986.

5. Tripathi D, Stanley AJ, Hayes PC, Patch D, Millson C, Mehrzad H, Austin A, Ferguson JW, Olliff SP, Hudson M, et al: U.K. guidelines on the management of variceal haemorrhage in cirrhotic patients. Gut 64: 1680-1704, 2015.

6. Bosch J and García-Pagán JC: Prevention of variceal rebleeding. Lancet 361: 952-954, 2003.

7. Brunner F, Berzigotti A and Bosch J: Prevention and treatment of variceal haemorrhage in 2017. Liver Int 37 (Suppl 1): S104-S115, 2017. 
8. Gonzalez R, Zamora J, Gomez-Camarero J, Molinero LM, Bañares R and Albillos A: Meta-analysis: Combination endoscopic and drug therapy to prevent variceal rebleeding in cirrhosis. Ann Intern Med 149: 109-122, 2008

9. Ravipati M, Katragadda S, Swaminathan PD, Molnar J and Zarling E: Pharmacotherapy plus endoscopic intervention is more effective than pharmacotherapy or endoscopy alone in the secondary prevention of esophageal variceal bleeding: A meta-analysis of randomized, controlled trials. Gastrointest Endosc 70: 658-664.e5, 2009.

10. Garcia-Tsao G, Abraldes J, Berzigotti A and Bosch J: Portal Hypertensive Bleeding in Cirrhosis: Risk Stratification, Diagnosis, and Management: 2016 practice guidance by the American association for the study of liver diseases Hepatology 65: 310-335, 2017.

11. Thiele M, Krag A, Rohde U and Gluud LL: Meta-analysis: Banding ligation and medical interventions for the prevention of rebleeding from oesophageal varices. Aliment Pharmacol Ther 35: 1155-1165, 2012.

12. Puente A, Hernández-Gea V, Graupera I, Roque M, Colomo A, Poca M, Aracil C, Gich I, Guarner C and Villanueva C: Drugs plus ligation to prevent rebleeding in cirrhosis: An updated systematic review. Liver Int 34: 823-833, 2014.

13. Funakoshi N, Ségalas-Largey F, Duny Y, Oberti F, Valats JC, Bismuth M, Daurès JP and Blanc P: Benefit of combination $\beta$-blocker and endoscopic treatment to prevent variceal rebleeding: A meta-analysis. World J Gastroenterol 16: 5982-5992, 2010

14. Garcia-Tsao G, Abraldes JG, Berzigotti A and Bosch J: Portal hypertensive bleeding in cirrhosis: Risk stratification, diagnosis, and management: 2016 practice guidance by the American Association for the study of liver diseases. Hepatology 65 : 310-335, 2017.

15. de Franchis R; BavenoV Faculty: Expanding consensus in portal hypertension: Report of the Baveno VI Consensus Workshop: stratifying risk and individualizing care for portal hypertension. J Hepatol 63: 743-752, 2015.

16. Chen J, Zeng XQ, Ma LL, Huang XQ, Tseng YJ, Wang J, Luo TC and Chen SY: Long-term efficacy of endoscopic ligation plus cyanoacrylate injection with or without sclerotherapy for variceal bleeding. J Dig Dis 17: 252-259, 2016.

17. Rücker G and Schwarzer G: Ranking treatments in frequentist network meta-analysis works without resampling methods. BMC Med Res Methodol 15: 58, 2015.

18. Schwarzer G, Carpenter J and Rücker G: Netmeta: Network meta-analysis with R (2016). R Package Version 0.9-2. netmeta, Cited February 22, 2016. Available from http://CRAN.R-project. org/package $=$ netmeta.

19. Gupta V, Rawat R, Shalimar and Saraya A: Carvedilol versus propranolol effect on hepatic venous pressure gradient at 1 month in patients with index variceal bleed: RCT. Hepatol Int 11: $181-187,2016$.

20. Sauerbruch T, Mengel M, Dollinger M, Zipprich A, Rössle M, Panther E, Wiest R, Caca K, Hoffmeister A, Lutz H, et al: Prevention of rebleeding from esophageal varices in patients with cirrhosis receiving small-diameter stents versus hemodynamically controlled medical therapy. Gastroenterology 149: p. 660-688.e1, 2015

21. Luo X, Wang Z, Tsauo J, Zhou B, Zhang H and Li X: Advanced cirrhosis combined with portal vein thrombosis: A randomized trial of TIPS versus endoscopic band ligation plus propranolol for the prevention of recurrent esophageal variceal bleeding. Radiology 276: 286-293, 2015.

22. Kumar P, Saxena KN, Misra SP and Dwivedi M: Secondary prophylaxis of variceal hemorrhage: A comparative study of band ligation, carvedilol and propranolol plus isosorbide mononitrate. Ind J Gastroenterology 34: A54, 2015.

23. Kong DR, Wang JG, Chen C, Yu FF, Wu Q and Xu JM: Effect of intravariceal sclerotherapy combined with esophageal mucosal sclerotherapy using small-volume sclerosant for cirrhotic patients with high variceal pressure. World J Gastroenterol 21: 2800-2806, 2015.

24. Kumar A, Jha SK, Sharma P, Dubey S, Tyagi P, Sharma BC and Sarin SK: Addition of propranolol and isosorbide mononitrate to endoscopic variceal ligation does not reduce variceal rebleeding incidence. Gastroenterology 137: 892-901, 2009.

25. Sauer P, Hansmann J, Richter GM, Stremmel W and Stiehl A: Endoscopic variceal ligation plus propranolol vs. transjugular intrahepatic portosystemic stent shunt: A long-term randomized trial. Endoscopy 34: 690-697, 2002.
26. Gülberg V, Schepke M, Geigenberger G, Holl J, Brensing KA, Waggershauser T, Reiser M, Schild $\mathrm{HH}$, Sauerbruch T and Gerbes AL: Transjugular intrahepatic portosystemic shunting is not superior to endoscopic variceal band ligation for prevention of variceal rebleeding in cirrhotic patients: A randomized, controlled trial. Scand J Gastroenterol 37: 338-343, 2002.

27. Escorsell A, Bañares R, García-Pagán JC, Gilabert R, Moitinho E, Piqueras B, Bru C, Echenagusia A, Granados A and Bosch J: TIPS versus drug therapy in preventing variceal rebleeding in advanced cirrhosis: A randomized controlled trial. Hepatology 35: 385-392, 2002.

28. Villanueva C, Miñana J, Ortiz J, Gallego A, Soriano G, Torras X, Sáinz S, Boadas J, Cussó X, Guarner C and Balanzó J: Endoscopic ligation compared with combined treatment with nadolol and isosorbide mononitrate to prevent recurrent variceal bleeding. N Engl J Med 345: 647-655, 2001.

29. Pomier-Layrargues G, Villeneuve JP, Deschênes M, Bui B, Perreault P, Fenyves D, Willems B, Marleau D, Bilodeau M, Lafortune $M$ and Dufresne MP: Transjugular intrahepatic portosystemic shunt (TIPS) versus endoscopic variceal ligation in the prevention of variceal rebleeding in patients with cirrhosis: A randomised trial. Gut 48: 390-396, 2001.

30. Narahara Y, Kanazawa H, Kawamata H, Tada N, Saitoh H, MatsuzakaS,Osada Y,Mamiya Y,NakatsukaK, YoshimotoH,etal: A randomized clinical trial comparing transjugular intrahepatic portosystemic shunt with endoscopic sclerotherapy in the long-term management of patients with cirrhosis after recent variceal hemorrhage. Hepatol Res 21: 189-198, 2001.

31. Hou MC, Chen WC, Lin HC, Lee FY, Chang FY and Lee SD: A new 'sandwich' method of combined endoscopic variceal ligation and sclerotherapy versus ligation alone in the treatment of esophageal variceal bleeding: A randomized trial. Gastrointest Endosc 53: 572-578, 2001

32. Meddi P, Merli M,Lionetti R, De Santis A, Valeriano V, Masini A, Rossi P, Salvatori F, Salerno F, de Franchis R, et al: Cost analysis for the prevention of variceal rebleeding: A comparison between transjugular intrahepatic portosystemic shunt and endoscopic sclerotherapy in a selected group of Italian cirrhotic patients. Hepatology 29: 1074-1077, 1999.

33. García-Villarreal L, Martínez-Lagares F, Sierra A, Guevara C, Marrero JM, Jiménez E, Monescillo A, Hernández-Cabrero T, Alonso JM and Fuentes R: Transjugular intrahepatic portosystemic shunt versus endoscopic sclerotherapy for the prevention of variceal rebleeding after recent variceal hemorrhage. Hepatology 29: 27-32, 1999.

34. Sauer P, Theilmann L, Stremmel W, Benz C, Richter G and Stiehl A: Transjugular intrahepatic portosystemic stent shunt versus sclerotherapy plus propranolol for variceal rebleeding. Gastroenterology 113: 1623-1631, 1997.

35. Sanyal AJ, Freedman AM, Luketic VA, Purdum PP III, Shiffman ML, Cole PE, Tisnado J and Simmons S: Transjugular intrahepatic portosystemic shunts compared with endoscopic sclerotherapy for the prevention of recurrent variceal hemorrhage. a randomized, controlled trial. Ann Intern Med 126: 849-857, 1997.

36. Villanueva C, Balanzó J, Novella MT, Soriano G, Sáinz S, Torras X, Cussó X, Guarner C and Vilardell F: Nadolol plus isosorbide mononitrate compared with sclerotherapy for the prevention of variceal rebleeding. N Engl J Med 334: 1624-1629, 1996.

37. Li P, Kong RD, Xie HJ, Sun B and Xu JM: Efficacy and safety of endoscopic variceal ligation and endoscopic injection sclerotherapy in patients with cirrhosis and esophageal varices: A prospective study. World Chinese J Digestology 18: 3791-3795, 2010.

38. Holster IL, Tjwa E, Moelker A, Wils A, Hansen BE, Vermeijden JR, Scholten P, van Hoek B, Nicolai JJ, Kuipers EJ, et al: Covered transjugular intrahepatic portosystemic shunt versus endoscopic therapy $+\beta$-blocker for prevention of variceal rebleeding. Hepatology 63: 581-589, 2016.

39. van Buuren HR, Groeneweg M, Vleggaar FP, Lesterrhuis W, Van Tillburg AJP, Hop WCJ, Peiterman H, Schalam SW, van Hout BA and Lameris JS: The results of a randomized controlled trial evaluating TIPS and endoscopic therapy in cirrhotic patients with gastro-esophageal variceal bleeding. J Hepatol 32: 71, 2000.

40. Cabrera J, Maynar M, Granados R, Gorriz E, Reyes R, Pulido-Duque JM, Rodriguez SanRoman JL, Guerra C and Kravetz D: Transjugular intrahepatic portosystemic shunt versus sclerotherapy in the elective treatment of variceal hemorrhage. Gastroenterology 110: 832-839, 1996. 
41. Dobrucali A, Bal K, Tuncer M, Ilkova F, Celik A, Uzunismail H, Yurdakul I and Oktay E: Endoscopic banding ligation compared with sclerotherapy for the treatment of esophageal varies. Turk J Gastroenterol 9: 340-344, 1998.

42. Holster IL, Moelker A, Tjwa ET, et al: Early transjugular intrahepatic portosystemic shunt (TIPS) as compared to endoscopic treatment reduces rebleeding but not mortality in cirrhotic patients with a 1st or 2 nd episode of variceal bleeding: A multicentre randomized controlled trial. United European Gastroenterology Journal 1: A84, 2013.

43. Merli M, RiggioO, Capocaccia L, et al: TIPS vs sclerotherapy in preventing variceal rebleeding in cirrhotic patients: Preliminary results of a randomised controlled trial (EASL abstract). Journal of hepatology 21: S41, 1994.

44. Ahmad I, Khan AA, Alam A, Butt AK, Shafqat F and Sarwar S: Propranolol, isosorbide mononitrate and endoscopic band ligation-alone or in varying combinations for the prevention of esophageal variceal rebleeding. J Coll Physicians Surg Pak 19: 283-286, 2009

45. Argonz J, Kravetz D, Suarez A, Romero G, Bildozola M, Passamonti M, Valero J and Terg R: Variceal band ligation and variceal band ligation plus sclerotherapy in the prevention of recurrent variceal bleeding in cirrhotic patients: A randomized, prospective and controlled trial. Gastrointest Endosc 51: 157-163, 2000

46. Avgerinos A, Armonis A, Manolakopoulos S, Poulianos G, Rekoumis G, Sgourou A, Gouma P and Raptis S: Endoscopic sclerotherapy versus variceal ligation in the long-term management of patients with cirrhosis after variceal bleeding. A prospective randomized study. J Hepatol 26: 1034-1341, 1997.

47. Avgerinos A,Armonis A,Stefanidis G,Mathou N,Vlachogiannakos J, Kougioumtzian A, Triantos C, Papaxoinis C, Manolakopoulos S, Panani A and Raptis SA: Sustained rise of portal pressure after sclerotherapy, but not band ligation, in acute variceal bleeding in cirrhosis. Hepatology 39: 1623-1630, 2004.

48. Avgerinos A, Rekoumis G, Klonis C, Papadimitriou N, Gouma P, Pournaras S and Raptis S: Propranolol in the prevention of recurrent upper gastrointestinal bleeding in patients with cirrhosis undergoing endoscopic sclerotherapy. A randomized controlled trial. J Hepatol 19: 301-311, 1993.

49. Baroncini D, Milandri GL, Borioni D, Piemontese A, Cennamo V, Billi P, Dal Monte PP and D'Imperio N: A prospective randomized trial of sclerotherapy versus ligation in the elective treatment of bleeding esophageal varices. Endoscopy 29: 235-240, 1997.

50. García-Pagán JC, Villanueva C, Albillos A, Bañares R, Morillas R, Abraldes JG and Bosch J; Spanish Variceal Bleeding Study Group: Nadolol plus isosorbide mononitrate alone or associated with band ligation in the prevention of recurrent bleeding: A multicentre randomised controlled trial. Gut 58: 1144-1150, 2009.

51. Hou MC, Lin HC, Kuo BI, Chen CH, Lee FY and Lee SD Comparison of endoscopic variceal injection sclerotherapy and ligation for the treatment of esophageal variceal hemorrhage: A prospective randomized trial. Hepatology 21: 1517-1522, 1995.

52. Hou MC, Lin HC, Lee FY, Chang FY and Lee SD: Recurrence of esophageal varices following endoscopic reagent and impact on rebleeding: Comparison of sclerotherapy and ligation. J Hepatology 32: 202-208, 2000.

53. Lo GH, Lai KH, Cheng JS, Hwu JH, Chang CF, Chen SM and Chiang HT: A prospective, randomized trial of sclerotherapy versus ligation in the management of bleeding esophageal varices. Hepatology 22: 466-4671, 1995.
54. Lo GH, Lai KH, Cheng JS, Lin CK, Huang JS, Hsu PI and Chiang HT: Emergency banding ligation versus sclerotherapy for the control of active bleeding from esophageal varices. Hepatology 25: 1101-1104, 1997.

55. Peña J, Brullet E, Sanchez-Hernández E, Rivero M, Vergara M, Martin-Lorente JL and Garcia Suárez C: Variceal ligation plus nadolol compared with ligation for prophylaxis of variceal rebleeding: A multicenter trial. Hepatology 41: 572-578, 2005.

56. de la Peña J, Rivero M, Sanchez E, Fábrega E, Crespo J and Pons-Romero F: Variceal ligation compared with endoscopic sclerotherapy for variceal hemorrhage: Prospective randomized trial. Gastrointest Endosc 49: 417-423, 1999.

57. Romero G, Kravetz D, Argonz J, Vulcano C, Suarez A, Fassio E, Dominguez N, Bosco A, Muñoz A, Salgado P and Terg R: Comparative study between nadolol and 5-isosorbide mononitrate vs. Endoscopic band ligation plus sclerotherapy in the prevention of variceal rebleeding in cirrhotic patients: A randomized controlled trial. Aliment Pharmacol Ther 24: 601-611, 2006.

58. Stiegmann GV, Goff JS, Michaletz-Onody PA, Korula J, Lieberman D, Saeed ZA, Reveille RM, Sun JH and Lowenstein SR: Endoscopic sclerotherapy as compared with endoscopic ligation for bleeding esophageal varices. N Engl J Med 326: 1527-1532, 1992.

59. Umehara M, Onda M, Tajiri T, Toba M, Yoshida $H$ and Yamashita K: Sclerotherapy plus ligation versus ligation for the treatment of esophageal varices: A prospective randomized study. Gastrointest Endosc 50: 7-12, 1999.

60. Viazis N, Armonis A, Vlachogiannakos J, Rekoumis G, Stefanidis G, Papadimitriou N, Manolakopoulos S and Avgerinos A: Effects of endoscopic variceal treatment on oesophageal function: a prospective, randomized study. Eur J Gastroenterol Hepatol 14: 263-269, 2002.

61. Vinel JP, Lamouliatte H, Cales P, Combis JM, Roux D, Desmorat H, Pradere B, Barjonet G and Quinton A: Propranolol reduces the rebleeding rate during endoscopic sclerotherapy before variceal obliteration. Gastroenterology 102: 1760-173, 1992.

62. Zheng M, Chen Y, Bai J, Zeng Q, You J, Jin R, Zhou X, Shen H, Zheng Y and Du Z: Transjugular intrahepatic portosystemic shunt versus endoscopic therapy in the secondary prophylaxis of variceal rebleeding in cirrhotic patients: meta-analysis update. J Clin Gastroenterol 42: 507-516, 2008.

63. Chinese Society of Gastroenterology, Chinese Medical Association, Chinese Society of Endoscopy: Guidelines for the diagnosis and treatment of esophageal and gastric variceal bleeding in cirrhotic portal hypertension. Chinese Society of Hepatology, Chinese Medical Association. Chinese Medial Association. J Clin Hepatol 32: 203-219, 2016 (In Chinese).

64. Cotoras P, Faundez J and Candia R: Should we add beta-blockers to band ligation for secondary prophylaxis of variceal bleeding? Medwave 17 (Suppl 1): e6847, 2017.

This work is licensed under a Creative Commons Attribution-NonCommercial-NoDerivatives 4.0 International (CC BY-NC-ND 4.0) License. 